\title{
THEO
}

CHEM

\section{Toward an experimental bond order}

\author{
Joseph L. Jules, John R. Lombardi* \\ Department of Chemistry and Center for Analysis of Structures and Interfaces (CASI), The City College of New York (CCNY), \\ Convent Avenue at 138th Street, New York, NY 10031, USA
}

Received 13 August 2003; revised 30 September 2003; accepted 30 September 2003

\begin{abstract}
By inverting the Guggenheimer formula relating force constant to internuclear distance we derive an experimental expression for bond order, which can be applied throughout the periodic table to diatomic molecules as well as polyatomic molecules. Only two adjustable parameters are required except they must be modified somewhat for polar molecules, most hydrides, and certain triplet ground state molecules. An alternative, suggested by Bader, depends only on the electron density at the bond critical point. It is modified to make it more generally applicable and compatible with experimental results and we compare the two approaches.
\end{abstract}

(C) 2003 Elsevier B.V. All rights reserved.

Keywords: Polyatomic molecules; Guggenheimer formula; Hartree-Fock limit

\section{Introduction: bond orders and theory}

The concept of bond order has helped generations of chemists compare the relative strengths and stabilities of chemical bonds and therefore has been of considerable usefulness [1,2]. All chemists know what we mean by a single, double or triple bond. If pressed for a more specific explanation, we are likely to define the bond order as $1 / 2$ the difference between the number of bonding electrons and the number of anti-bonding electrons in a given bond. It is convenient to call this the formal bond order $\left(n_{F}\right)$. This definition, while simple to state, presents several difficulties. Firstly, in order to determine the bond order, we must know the number of bonding and

\footnotetext{
* Corresponding author. Tel.: +1-212-650-6032; fax: + 1-212650-6848.

E-mail address: lombardi@sci.ccny.cuny.edu (J.R. Lombardi).
}

anti-bonding electrons. To do this we must in some sense know the molecular configuration of the ground state of the molecule. While this is not difficult to determine for many common molecules, in fact for numerous molecules of interest, the correct configuration is not known, or at best is controversial [3]. This is especially true for molecules, which include heavy atoms from the lower reaches of the periodic table. These molecules often include atoms with open shell configurations (e.g. unfilled $d$ - or $f$ - orbitals), for which there are many low lying states, each of which could credibly be the ground state [4]. Furthermore, many modern calculations go well beyond the single determinant Hartree-Fock limit to include multiple configurations (CI). Recent complete active space multi-configurational self-consistent field calculations on ruthenium trimer, for example, have required some 45 million configurations [5] to describe the ground 
state adequately. A second difficulty with the formal definition of bond order is that it treats all orbitals as if they made an equivalent contribution to bonding. For example, electrons in a $\pi$-orbital are presumed to contribute equally to bond order as those in a $\sigma$-orbital. However, $\pi$-orbitals possess a nodal plane along the bond, and are thus devoid of electron density in the very region that $\sigma$-orbital makes its major contribution. When $\delta$-orbitals are considered, it becomes even more difficult to imagine that these relatively non-bonding electrons should be considered to contribute equally to chemical bonding. By considering the detailed contributions to the forces acting on atomic centers due to electronic charge distribution, Bader, Henneker and Cade [6] showed how an interpretation of bonding based only on electron counting, or population analysis can be quite misleading. In addition to the amount of charge involved in a bond, the exact disposition of the charge density, e.g. its diffuseness or areas of concentration are equally important.

It is clear that a more sophisticated definition of the bond order will allow for fractional values. [7] Coulson [8] and later Mulliken [9] examined the mobile contribution to bond orders due to the extensive delocalization of $\pi$-electrons. It is reasonable, for example, to presume that bond order is in some way proportional to the density of electrons between two atoms. Thus if $a_{\propto i}$ is the contribution of the $i$ th atomic orbital to the occupied $\propto$-molecular orbital, then we may write:

$n_{C}=p_{i j}=2 \sum_{\alpha}^{\text {occ }} a_{\alpha i} a_{\alpha j}$

Coulson then showed that the bond order may be written in terms of the force tending to change the length of the bond:

$n_{C}=-\frac{1}{2} \frac{\partial E}{\partial \beta}$

where $E$ is the total mobile binding energy and $\beta$ is the resonance integral. Boyd [10] criticized the Coulson definition of bond order since it is not necessarily invariant to a rotation of the coordinate system. He recommended that the bond order definition be limited to situations for which a particularly chosen sub-matrix of the population matrix has been properly block-diagonalized. This procedure leads to considerably more consistent values of the bond order. He suggested that the bond order concept might be a convenient practical means to investigate bond strengths and distances, especially in large molecules where semi-empirical methods cannot easily be used to calculate equilibrium geometries and force constants. Reed and Schleyer [11] include the number of covalently shared electron pairs and hybrid overlaps of natural atomic orbitals, in order to analyze the effects of hypervalency stemming from $d$-orbital occupation.

Cioslowski and Mixon [12] examined the covalent bond order in terms of the atomic overlap matrix $\langle i \mid j\rangle$ for an atom (A) of two spin orbitals integrated over an atomic basin [13] $\left(\Omega_{\mathrm{A}}\right)$ such that:

$\langle i \mid j\rangle_{A}=\int_{\Omega_{\mathrm{A}}} \phi_{i}^{*}(r) \phi_{j}(r) \mathrm{d} r$

Then the bond order between atoms A and B may be written as:

$P_{\mathrm{AB}}=2 \sum_{i}\langle i \mid i\rangle_{\mathrm{A}}\langle i \mid i\rangle_{\mathrm{B}}$

It can be seen that the contribution to the bond order from a doubly occupied localized orbital in a purely covalent bond between atoms $\mathrm{A}$ and $\mathrm{B}$ is exactly one. If instead the bond is completely ionic, the contribution is zero. For a somewhat polarized bond, the contribution is somewhere between one and zero. This definition of bond order has recently been used by Chestnut [14] to calculate the contribution of lone pairs to bonding.

Yamasaki and Goddard [15] utilize a correlation analysis of chemical bond operators on ab initio wave functions. They define the bond order operator $\mathbf{I}_{\mathrm{AB}}=-2 \boldsymbol{\sigma}_{\mathrm{AB}}$ in terms of the charge operator $\mathbf{q}$, such that:

$\sigma_{\mathrm{AB}}=\left(q_{\mathrm{A}}-\left\langle q_{\mathrm{A}}\right\rangle\right)\left(q_{\mathrm{B}}-\left\langle q_{\mathrm{B}}\right\rangle\right)$

In this approach, the bond order is interpreted as the statistical covariance of the charge operators for centers $\mathrm{A}$ and $\mathrm{B}$, i.e. the correlation between fluctuations of the electronic charges on each atom. Giambiagi, Giambiagi and Jorge [16] showed that this same covariant measure for a closed shell is an invariant of the second order reduced density matrix. 
Another approach, due to Wiberg [17], based on a suggestion of Salem [18], involves the sum of squares of bond orders. The bond index is defined as:

$\sum_{k} p_{j k}^{2}=2 p_{j j}-p_{j j}^{2}$

which is twice the atomic charge density minus the square of the charge density. This corresponds to the number of covalent bonds formed by an atom, but corrected for the ionic nature of each contributing bond. This may be seen to be similar to the bond order of Cioslowski and Mixon. The Wiberg bond index is invariant to coordinate rotations, but has been criticized by Boyd [10] as somewhat arbitrary, since there is no underlying theoretical reason for this definition. Also, he pointed out, the bond index tends to underestimate $\pi$-electron contributions and overestimate $\sigma$-electron contributions to bonding. Despite this, the bond index has found widespread use. Armstrong et al. [19] explored some of the applications of the Wiberg bond index. Natiello and Medrano [20] extended the bond index to ab initio calculations. Mayer [21] applied the bond index to open shell SCF wavefunctions and generalized it to include correlation effects. This work emphasized the need to account for the contribution of non-classical exchange energy to bonding. Fulton [22] observed that most of the definitions of bond order or bond index depend on the explicit assignment of orbitals to atomic centers, rather than the complete manyelectron wave function. He turned, then, to density matrix theory to describe the way a single electron in a many electron system is shared between any two points in space. The sharing index depends only on the first-order density matrix of the system and is thus independent of any definition of orbital structure, as well as invariant to coordinate transformations. It is a one-electron property of the system and is defined as the absolute value squared of the sharing amplitude. The sharing amplitude is simply the square root of the firstorder density matrix, and thus gives the probability that an electron is shared between two points. The bond index is related to the sharing index by integrating over the volumes assigned to the atoms of the molecule. These ideas were further refined by Fradera, Austen and Bader [23], who defined the atomic localization index $(\lambda(\mathrm{A}))$ as the integral around atom $\mathrm{A}$ of the Fermi hole density. The delocalization index $(\delta(\mathrm{A}, \mathrm{B}))$ between two atoms ( $\mathrm{A}$ and $\mathrm{B}$ ) is the integral of the Fermi density over two separate atoms. The Fermi density is the distribution of the Fermi hole, which is created in the pair density by the antisymmetrization requirement. The delocalization index measures the number of electrons, which are shared between two atoms. This is distinct from the bond order, which measures the number of Lewis-bonded pairs of electrons shared. More recently, Angyan, Rosta and Surjan [24] compared two definitions of bond order: that using the exchange part of the twoparticle density matrix with that using the covariance of fluctuations of the number of electrons between two different atomic centers. Both definitions produce the same results for singledeterminant wave functions, but the covariance based bond order produces somewhat lower values than the exchange definition using correlated wave functions.

One of the recurring difficulties, which run through many of the attempts to define a bond order in terms of quantum mechanical properties of molecules, is the inability to easily compare values derived from various types of bonds. It would be of considerable utility to be able to define certain geometrical parameters, which are readily identifiable and comparable from one molecule to another. Important strides have been made in this by the investigations of Bader and co-workers [13,25,26] into the topology of molecular bonding through examination of the total electron density $(\rho)$. Atomic basins were defined as being enclosed by a surface for which the vector $\mathbf{n}$ is perpendicular to the zero gradient function of the electron density, such that $\nabla \rho(r) \mathbf{n}=0$. These atomic basins provide a convenient and consistent method for dividing molecules into distinct atomic regions, enabling comparable measures of such properties as the atomic charge, as well as interatomic interactions related to bonding. These investigators further identified certain critical points $\left(\mathbf{r}=\mathbf{r}_{\mathrm{c}}\right)$ in the electron density for which the gradient of the density is zero $(\nabla \rho(\mathbf{r})=0)$. Examination must then be made of the exact nature of the critical points to determine whether they are maxima, minima or 
saddle points. This is carried out by defining the Hessian matrix:

$H(i, j)=\frac{\partial^{2} \rho}{\partial x_{i} \partial x_{j}}$

The trace of the Hessian matrix, which itself is an invariant, is known as the Laplacian:

$\nabla^{2} \rho=\frac{\partial^{2} \rho}{\partial x^{2}}+\frac{\partial^{2} \rho}{\partial y^{2}}+\frac{\partial^{2} \rho}{\partial z^{2}}$

In regions of space where $\nabla^{2} \rho<0$, electronic charge is concentrated such as in covalent or polar molecules, while for molecules where $\nabla^{2} \rho>0$ electronic charge is depleted, as in noble gas, ionic and hydrogen bonded molecules. The Hessian matrix may be diagonalized to yield the principal axes of curvature, where the eigenvalues are $\left(\lambda_{1}, \lambda_{2}, \lambda_{3},\right)$. The critical points $\mathbf{r}_{\mathrm{c}}$ (of $\nabla \rho=0$ ) are characterized by two numbers $(\omega, \sigma)$, where $\omega$ is known as the rank, and $\sigma$ is the signature of the Hessian matrix. The rank is the number of non-zero eigenvalues of the Hessian matrix, while the signature is determined as the sum of the signs of the eigenvalues. Most critical points have $\omega=3$. Covalent bonds, which typically have large values of $\rho$, are characterized by $(\omega, \sigma)=(3,-1)$. The positive eigenvalue $\left(\lambda_{3}\right)$ is associated with the direction joining two covalently bonded atoms, and defines the bond path (which may be curved for a strained bond, e.g. cyclopropane). The two negative eigenvalues $\left(\lambda_{1}, \lambda_{2}\right)$ define the ellipticity of the bond:

$\varepsilon=\left|\frac{\lambda_{1}-\lambda_{2}}{\lambda_{2}}\right|$

The ellipticity increases with the $\pi$ character of a double bond but goes back to zero for a triple bond. Bader and co-workers [27] were also able to show a relationship between the bond order $\left(n_{\mathrm{B}}\right)$ and the electron density at a critical point $\left(\rho_{\mathrm{b}}=\rho\left(\mathbf{r}_{\mathrm{c}}\right)\right)$ such that:

$n_{\mathrm{B}}=\exp \left(A\left(\rho_{\mathrm{b}}-B\right)\right)$

A simple physical interpretation can be made for the empirical constants $A$ and $B . B$ is clearly the electron density at the critical point for a single bond $\left(n_{\mathrm{B}}=1\right)$, while taking derivatives we find $A=\mathrm{d} \ln \left(n_{\mathrm{B}}\right) / \mathrm{d} \rho_{\mathrm{b}}$ represents the fractional increase in bond order due to a unit increase in electron density. Using $n_{\mathrm{B}}=1,2,3$ for bond orders of a $\mathrm{C}-\mathrm{C}$ bond in ethane, ethylene and acetylene, Bader found values of $A=0.957$ and $B=1.70$ using, for example, a single determinant SCF calculation at a level of approximation with a $6-31 G^{*}$ basis set. This definition has found considerable use such as the examination of homoaromaticity [28], and electronic reorganization during the progress of chemical reactions [29]. More recently, Howard and Lamarche [30] have examined in considerable depth, the application of charge density topology to covalent bond orders. They have obtained bond orders using the definition of Cioslowski and Mixon [12] Eq. (4) with B3LYP/6$31+\mathrm{G}^{* *}$ level calculations, examining the extent of contributions of terms including the Laplacian, the kinetic energy density as well as terms in the critical density.

Although these versions of bond order are quite useful in obtaining realistic comparative measures of bonding, they all require an accurate ground state wave function or electron density function. Even though recent advances in computational power and theoretical methods have enabled considerable improvements in our ability to obtain accurate ground state wave functions, there are still many molecules for which such accuracy is unattainable. It would therefore be of interest to examine possible expressions for bond order, which depend entirely on experimental parameters. If such an expression could be developed, it would not only be useful directly as an experimental measure of bond strength, but would also be of use to theory, enabling for example attempts to sort out the correct ground state of a molecule for which several low lying states are predicted theoretically. It is clear from the above discussion, that a useful experimental bond order would satisfy the following criteria:

1. It would be determined by easily measurable experimental values.

2. It would require as few adjustable parameters as possible.

3. It would be applicable throughout the periodic table.

4. Bond orders for a single bond would be near one, for a double bond would be less than two and for a triple bond would be less than three, etc. 
In Section 2, we review several of the previously suggested experimental expressions for bond order, and by inverting a relationship due to Guggenheimer [31], present a new definition, which we believe is equally applicable in all parts of the periodic table. We then apply our expression to numerous diatomic molecules, and then extend it to the realm of polyatomic molecules as well. We also examine recent experiments, which enable the accurate determination of electron density at bond critical points. These provide an experimental approach to determination of the bond order suggested by Bader Eq. (10).

\section{Experimental bond orders}

One of the earliest attempts to define an experimental bond order was due originally to Pauling [1]. This was made more explicit by Johnston [32], who showed that the bond order could be expressed in terms of experimental force constants by:

$n_{P}=k_{\mathrm{e}}^{(n)} / k_{\mathrm{e}}^{(1)}$

where $k_{\mathrm{e}}^{(n)}$ is the measured stretching force constant for a bond and $k_{\mathrm{e}}^{(1)}$ is the force constant for a single bond. This is a very attractive definition, due to its sheer simplicity. We have, in fact recently applied this relationship to the transition metal dimers, both in a recent review [33], and an analysis of the relationship between force constant and internuclear distance [34]. The transition metal dimers are composed of atoms with either a $\mathrm{d}^{N} \mathrm{~s}^{1}$ or $\mathrm{d}^{N-1} \mathrm{~s}^{2}$ configuration. Good chemical bonding, however, is achieved only with the former configuration, so that any atom with an $\mathrm{s}^{2}$ ground state requires additional $\mathrm{s} \rightarrow \mathrm{d}$ promotional energy to form a strong $\sigma$-bond. In order to include such promotional energy, knowledge of the configuration of the dissociation products must be obtained. This is one of the reasons force constants rather than dissociation energies are more useful for measuring bond orders [33]. The coinage metal dimers $\left(\mathrm{Cu}_{2}\right.$, $\mathrm{Ag}_{2}$, and $\mathrm{Au}_{2}$ ) must derive from atoms with a $\mathrm{d}^{10} \mathrm{~s}^{1}$ configuration. The filled d-orbital precludes the participation of d-electrons in bonding and thus we may take the force constant for these species as necessarily representing a single $\sigma$ bond for each row of the periodic table. These ideas were applied with considerable success to the remaining transition metal dimers, providing quite reasonable expressions for the bond orders across the d-block of the periodic table in these cases. Measures of the relative contribution of $d$ electrons to the bonding in these species could readily be extracted, since accurate experimental force constants are available for almost all the transition metal dimers. In a later work, these ideas were extended to explore the relationship between force constant and internuclear distance in transition metal dimers, at least in those cases for which accurate internuclear distances have been measured [34].

The success in applying Pauling's experimental bond order to transition metal dimers encourages the possibility of extending these results to other parts of the periodic table. Unfortunately attempts to carry this out fail. The problem is in determining a value for $k_{\mathrm{e}}^{(1)}$, since there are many possible species which have simply a $\sigma^{2}$ configuration and thus possess a formal single bond. For example, it might be natural to take the force constant for $\mathrm{H}_{2}$ as a reference single bond. However, if this is done, then we obtain a value of 3.98 for $\mathrm{N}_{2}, 0.046$ for $\mathrm{Li}_{2}$ and 0.230 for $\mathrm{Cu}_{2}$. The value for $\mathrm{N}_{2}$ is much too high to represent a triple bond, while those for $\mathrm{Li}_{2}$ and $\mathrm{Cu}_{2}$ are much too low to represent a single bond. Clearly, the Pauling formula is not easily extended to other regions of the periodic table. The problem is that there are great variations in the size of atomic orbitals as we move across the periodic table, so that the definition of a single bond as formed by two electrons in a $\sigma$-molecular orbital must take into account the resulting variations in the internuclear distance. This was not too much a problem for the transition metal dimers, since the internuclear distances do not vary much in that restricted region of the periodic table (e.g. for species with $n_{\mathrm{P}} \geq 1, r_{\mathrm{e}}$ ranges from 1.7 to $2.5 \AA$ ). We might, then, expect a viable definition of bond order to include contributions from the internuclear distance as well as the force constant. In fact, much of the literature concerning this topic involves examination of either the relationship of bond order to internuclear distance [2] or the relationship between force constant and internuclear distance [34], often with the bond order as mediator. For example the work of Kavanau [35] suggested that the internuclear distance could be written as a function of principal quantum numbers 
raised to the power of the bond order. Gordy [36] suggested instead that the force constant was linearly proportional to the bond order, and inversely related to the internuclear distance to the power $3 / 2$. In each case, the value of the bond order was assumed to be known (and chosen as an integer). We have examined the possibility of inverting these relationships, solving for the bond order, for use as a possible definition for an experimental bond order. However, the results were either not applicable to various parts of the periodic table, or required too many adjustable parameters to be of much use in this regard. A more direct approach was suggested by Politzer, Borkman, Parr and co-workers [37-42]. By examining the potential energy function for diatomic molecules, they were able to define both the magnitude of the point charge in the center of a bond and the effective particle-in-a-box length. Through these parameters, they were able to determine internuclear distances and force constants, and to derive a relationship for the bond order, which can be most simply written:

$n_{\mathrm{PBP}}=0.557\left(\frac{k_{\mathrm{e}}}{r_{\mathrm{e}}}\right)^{1 / 2}$

This formula is attractive, in that it takes account of variations in bond length as well as force constant, has only one adjustable parameter, and is simple. However, since then we have obtained considerably more experimental data. For example, if we apply this formula to the transition metal dimers, we obtain values of $0.43,0.38$ and 0.52 for the formally single bonds of $\mathrm{Cu}_{2}, \mathrm{Ag}_{2}$, and $\mathrm{Au}_{2}$. For the relatively strong $\mathrm{Mo}_{2}$ bond (for which Pauling's relationship gives 5.38) we obtain a value of only 1.01. Jug [43] suggests that since Politzer's bond order relationship produces single bond values as disparate as 1.55 for $\mathrm{H}_{2}$ and 0.172 for $\mathrm{Li}_{2}$, it is not bond order but bond energies, which are being measured.

Another relationship, which has found some success in relating force constant and internuclear distance is due to Guggenheimer [31], who showed that the formula

$k_{\mathrm{e}}=C\left(z_{1} z_{2}\right)^{1 / 2} r_{\mathrm{e}}^{-s}$

can be applied to a broad selection of diatomic molecules with a single bond. The values of $z_{1}$ and $z_{2}$ are the number of electrons in the valence shell of atoms 1 and 2. The parameters $C$ and $s$ were chosen to give a best fit to the series $\mathrm{H}_{2}, \mathrm{Li}_{2}, \mathrm{Na}_{2}, \mathrm{~K}_{2}$. These best values are found to be $C=2.738$ (if $k_{\mathrm{e}}$ is in mdyne/Å) and $s=2.46$. Guggenheimer then calculated values of $k_{\mathrm{e}}$ for over 70 diatomic molecules from various regions of the periodic table and fit the observed vibrational frequencies with an average deviation of $1.6 \%$. It is worth noting that almost all of these molecules coincide with those for which Bader and Essen [26] found $\nabla^{2} \rho\left(r_{\mathrm{c}}\right)<0$, i.e. charge tends to be concentrated near the bond critical point. We have recently extended the Guggenheimer relationship to dimers of transition metals [34] with similarly impressive results. In order to apply this to more ionic molecules (including most hydrides, and halides of alkali and alkaline earth metals, but also molecules with a ground triplet state, such as $\mathrm{O}_{2}, \mathrm{SO}, \mathrm{S}_{2}$ ) Guggenheimer found that good fits could be obtained with alternate values of $C=2.491$ and $s=1.84$. It is worth noting that the set of molecules for which Guggenheimer required a different set of parameters, are almost identical to those found by Bader and Essen [26] to have $\nabla^{2} \rho\left(r_{\mathrm{c}}\right)>0$. These molecules are those for which, at the critical point, electronic charge is depleted, as in noble gas, ionic and hydrogen bonded molecules. In the following (except for triplet ground state molecules), to the extent we have information as to the sign of $\nabla^{2} \rho\left(r_{\mathrm{c}}\right)$, we use $s=2.46$ for negative values of the Laplacian and $s=$ 1.84 for positive values.

In order to take account of the possibility of multiple bonding, Guggenheimer found it necessary to multiply the right hand side of Eq. (13) by a factor of 1.905. This is consistent with results found previously by Pauling, which indicate that the force constant is proportional to the bond order. In order to derive a corresponding expression for bond order, the foregoing suggests we insert the bond order, $n$, as a mulitplicative factor on the right side of Eq. (13) and carry out an inversion of the Guggenheimer relationship, defining the bond order as:

$n=\frac{k_{\mathrm{e}} r_{\mathrm{e}}^{s}}{C\left(z_{1} z_{2}\right)^{1 / 2}}$

Using this definition, and the parameters obtained by Guggenheimer for $C$ and $s$, we have calculated bond orders for numerous diatomic molecules, listed in Tables 1-4. In Table 1 we have calculated the bond 
Table 1

Bond orders for diatomic molecules using Eq. (14), with $C=2.738$ and $s=2.46$

\begin{tabular}{|c|c|c|c|c|c|c|c|c|}
\hline Species & & & $\omega_{\mathrm{e}}$ & $k_{\mathrm{e}}$ & $r_{\mathrm{e}}$ & $z_{1}$ & $z_{2}$ & $n$ \\
\hline $\mathrm{H}_{2}$ & 0 & 0 & 4405.3 & 5.774 & 0.741 & 1 & 1 & 1.01 \\
\hline $\mathrm{Li}_{2}$ & 1 & 1 & 361.3 & 0.267 & 2.672 & 1 & 1 & 1.09 \\
\hline $\mathrm{LiNa}$ & 1 & 2 & 256.8 & 0.209 & 2.810 & 1 & 1 & 0.97 \\
\hline $\mathrm{LiK}$ & 1 & 3 & 207.0 & 0.149 & 3.300 & 1 & 1 & 1.02 \\
\hline $\mathrm{LiCs}$ & 1 & 3 & 167.0 & 0.108 & 3.550 & 1 & 1 & 0.89 \\
\hline $\mathrm{LiRb}$ & 1 & 4 & 185.0 & 0.129 & 3.420 & 1 & 1 & 0.97 \\
\hline $\mathrm{Na}_{2}$ & 2 & 2 & 159.2 & 0.172 & 3.079 & 1 & 1 & 1.00 \\
\hline $\mathrm{NaK}$ & 2 & 3 & 123.2 & 0.129 & 3.500 & 1 & 1 & 1.03 \\
\hline $\mathrm{NaRb}$ & 2 & 4 & 106.6 & 0.121 & 3.630 & 1 & 1 & 1.06 \\
\hline $\mathrm{NaCs}$ & 2 & 5 & 97.0 & 0.109 & 3.750 & 1 & 1 & 1.03 \\
\hline $\mathrm{K}_{2}$ & 3 & 3 & 92.0 & 0.097 & 3.905 & 1 & 1 & 1.01 \\
\hline $\mathrm{Rb}_{2}$ & 4 & 4 & 56.8 & 0.081 & 4.180 & 1 & 1 & 1.00 \\
\hline $\mathrm{RbCs}$ & 4 & 4 & 49.4 & 0.075 & 4.300 & 1 & 1 & 0.99 \\
\hline $\mathrm{Cs}_{2}$ & 5 & 5 & 42.0 & 0.069 & 4.420 & 1 & 1 & 0.98 \\
\hline $\mathrm{HB}$ & 0 & 1 & 2366.0 & 3.019 & 1.233 & 1 & 3 & 1.06 \\
\hline $\mathrm{HC}$ & 0 & 1 & 2824.0 & 4.337 & 1.120 & 1 & 4 & 1.05 \\
\hline $\mathrm{HN}$ & 0 & 1 & 3300.0 & 5.989 & 1.038 & 1 & 5 & 1.07 \\
\hline $\mathrm{HO}$ & 0 & 1 & 3728.0 & 7.779 & 0.971 & 1 & 6 & 1.08 \\
\hline $\mathrm{HF}$ & 0 & 1 & 4141.3 & 9.691 & 0.917 & 1 & 7 & 1.08 \\
\hline $\mathrm{HO}^{+}$ & 0 & 1 & 3113.4 & 5.414 & 1.028 & 1 & 5 & 0.95 \\
\hline $\mathrm{LiO}$ & 1 & 1 & 745.0 & 1.595 & 1.695 & 1 & 6 & 0.87 \\
\hline $\mathrm{Na}_{2}^{+}$ & 2 & 2 & 126.0 & 0.108 & 3.540 & 1 & 8 & 0.31 \\
\hline $\mathrm{Mg}_{2}$ & 2 & 2 & 51.1 & 0.018 & 3.891 & 2 & 2 & 0.10 \\
\hline $\mathrm{Ca}_{2}$ & 3 & 3 & 64.9 & 0.050 & 4.277 & 2 & 2 & 0.32 \\
\hline $\mathrm{Al}_{2}$ & 2 & 2 & 350.0 & 0.974 & 2.466 & 3 & 3 & 1.09 \\
\hline $\mathrm{ZnF}$ & 3 & 1 & 619.5 & 3.329 & 1.590 & 2 & 7 & 1.02 \\
\hline $\mathrm{ZnI}$ & 3 & 4 & 223.4 & 1.269 & 2.420 & 2 & 7 & 1.09 \\
\hline CdI & 4 & 4 & 178.5 & 1.119 & 2.560 & 2 & 7 & 1.10 \\
\hline $\mathrm{HgF}$ & 5 & 1 & 490.8 & 2.463 & 1.740 & 2 & 7 & 0.94 \\
\hline $\mathrm{HgCl}$ & 5 & 2 & 293.8 & 1.532 & 2.230 & 2 & 7 & 1.08 \\
\hline $\mathrm{HgBr}$ & 5 & 3 & 186.2 & 1.167 & 2.440 & 2 & 7 & 1.02 \\
\hline $\mathrm{HgI}$ & 5 & 4 & 125.0 & 0.716 & 2.550 & 2 & 7 & 0.70 \\
\hline $\mathrm{BN}$ & 1 & 1 & 1514.6 & 8.331 & 1.281 & 3 & 5 & 1.44 \\
\hline $\mathrm{C}_{2}$ & 1 & 1 & 1641.7 & 9.536 & 1.312 & 4 & 4 & 1.70 \\
\hline $\mathrm{Si}_{2}$ & 2 & 2 & 511.0 & 2.152 & 2.246 & 4 & 4 & 1.44 \\
\hline $\mathrm{SiC}$ & 2 & 1 & 983.0 & 4.781 & 1.820 & 4 & 4 & 1.90 \\
\hline $\mathrm{BO}$ & 1 & 1 & 1885.4 & 13.512 & 1.205 & 3 & 6 & 1.84 \\
\hline $\mathrm{AlO}$ & 2 & 1 & 979.2 & 5.676 & 1.618 & 3 & 6 & 1.60 \\
\hline AlS & 2 & 2 & 617.1 & 3.286 & 2.029 & 3 & 6 & 1.61 \\
\hline $\mathrm{CN}$ & 1 & 1 & 2068.7 & 16.305 & 1.172 & 4 & 5 & 1.97 \\
\hline $\mathrm{CP}$ & 1 & 2 & 1240.0 & 7.840 & 1.562 & 4 & 5 & 1.92 \\
\hline $\mathrm{SiN}$ & 2 & 1 & 1152.0 & 7.309 & 1.572 & 4 & 5 & 1.82 \\
\hline PO & 2 & 1 & 1231.0 & 9.419 & 1.447 & 4 & 5 & 1.91 \\
\hline $\mathrm{AsO}$ & 3 & 1 & 960.6 & 7.168 & 1.610 & 4 & 5 & 1.89 \\
\hline $\mathrm{SiP}$ & 2 & 2 & 615.7 & 3.290 & 2.078 & 4 & 5 & 1.62 \\
\hline $\mathrm{N}_{2}^{+}$ & 1 & 1 & 2207.0 & 20.093 & 1.116 & 4 & 5 & 2.15 \\
\hline $\mathrm{P}_{2}^{+}$ & 2 & 2 & 672.2 & 4.123 & 1.985 & 4 & 5 & 1.82 \\
\hline
\end{tabular}

Table 1 (continued)

\begin{tabular}{lllllll}
\hline Species & $\omega_{\mathrm{e}}$ & $k_{\mathrm{e}}$ & $r_{\mathrm{e}}$ & $z_{1}$ & $z_{2}$ & $n$ \\
\hline
\end{tabular}

$\begin{array}{lllllllll}\mathrm{BF} & 1 & 1 & 1402.1 & 8.069 & 1.263 & 3 & 7 & 1.14\end{array}$

$\begin{array}{lllllllll}\mathrm{BCl} & 1 & 2 & 839.1 & 3.474 & 1.715 & 3 & 7 & 1.04\end{array}$

$\begin{array}{lllllllll}\mathrm{BBr} & 1 & 3 & 686.3 & 2.642 & 1.870 & 3 & 7 & 0.98\end{array}$

$\begin{array}{lllllllll}\mathrm{AlF} & 2 & 1 & 802.3 & 4.229 & 1.654 & 3 & 7 & 1.16\end{array}$

$\begin{array}{lllllllll}\mathrm{AlCl} & 2 & 2 & 481.3 & 2.091 & 2.060 & 3 & 7 & 0.99\end{array}$

$\begin{array}{lllllllll}\mathrm{AlBr} & 2 & 3 & 379.2 & 1.709 & 2.210 & 3 & 7 & 0.96\end{array}$

$\begin{array}{lllllllll}\text { AlI } & 2 & 4 & 316.1 & 1.310 & 2.530 & 3 & 7 & 1.02\end{array}$

$\begin{array}{lllllllll}\mathrm{GaF} & 3 & 1 & 622.2 & 3.397 & 1.774 & 3 & 7 & 1.11\end{array}$

$\begin{array}{lllllllll}\mathrm{GaCl} & 3 & 2 & 365.0 & 1.845 & 2.250 & 3 & 7 & 1.08\end{array}$

$\begin{array}{lllllllll}\mathrm{GaBr} & 3 & 3 & 263.0 & 1.517 & 2.370 & 3 & 7 & 1.01\end{array}$

$\begin{array}{lllllllll}\mathrm{GaI} & 3 & 4 & 216.4 & 1.242 & 2.540 & 3 & 7 & 0.98\end{array}$

$\begin{array}{lllllllll}\mathrm{InF} & 4 & 1 & 535.4 & 2.753 & 1.985 & 3 & 7 & 1.19\end{array}$

$\begin{array}{lllllllll}\mathrm{InCl} & 4 & 2 & 316.8 & 1.602 & 2.430 & 3 & 7 & 1.13\end{array}$

$\begin{array}{lllllllll}\mathrm{InBr} & 4 & 3 & 221.0 & 1.356 & 2.550 & 3 & 7 & 1.08\end{array}$

$\begin{array}{lllllllll}\text { InI } & 4 & 4 & 177.1 & 1.114 & 2.720 & 3 & 7 & 1.04\end{array}$

$\begin{array}{lllllllll}\mathrm{TIF} & 5 & 1 & 477.3 & 2.334 & 2.084 & 3 & 7 & 1.13\end{array}$

$\begin{array}{lllllllll}\mathrm{TICl} & 5 & 2 & 287.5 & 1.471 & 2.460 & 3 & 7 & 1.07\end{array}$

$\begin{array}{lllllllll}\mathrm{TIBr} & 5 & 3 & 192.5 & 1.254 & 2.580 & 3 & 7 & 1.03\end{array}$

$\begin{array}{lllllllll}\text { TII } & 5 & 4 & 150.0 & 1.038 & 2.750 & 3 & 7 & 1.00\end{array}$

$\begin{array}{lllllllll}\mathrm{CO} & 1 & 1 & 2168.0 & 18.999 & 1.128 & 4 & 6 & 1.91\end{array}$

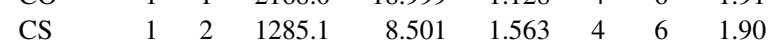

$\begin{array}{lllllllll}\mathrm{CSe} & 1 & 3 & 1035.4 & 6.591 & 1.676 & 4 & 6 & 1.75\end{array}$

$\begin{array}{lllllllll}\mathrm{SiO} & 2 & 1 & 1242.0 & 9.265 & 1.510 & 4 & 6 & 1.90\end{array}$

$\begin{array}{lllllllll}\mathrm{SiS} & 2 & 2 & 749.5 & 4.955 & 2.010 & 4 & 6 & 2.06\end{array}$

$\begin{array}{lllllllll}\mathrm{SiSe} & 2 & 3 & 580.0 & 4.107 & 2.140 & 4 & 6 & 1.99\end{array}$

$\begin{array}{lllllllll}\mathrm{SiTe} & 2 & 4 & 480.4 & 3.130 & 2.340 & 4 & 6 & 1.89\end{array}$

$\begin{array}{lllllllll}\mathrm{GeO} & 3 & 1 & 985.6 & 7.504 & 1.651 & 4 & 6 & 1.92\end{array}$

$\begin{array}{lllllllll}\mathrm{GeS} & 3 & 2 & 575.8 & 4.392 & 2.060 & 4 & 6 & 1.94\end{array}$

$\begin{array}{lllllllll}\mathrm{GeSe} & 3 & 3 & 406.8 & 3.758 & 2.190 & 4 & 6 & 1.93\end{array}$

$\begin{array}{lllllllll}\mathrm{GeTe} & 3 & 4 & 323.4 & 2.918 & 2.390 & 4 & 6 & 1.86\end{array}$

$\begin{array}{lllllllll}\mathrm{SnO} & 4 & 1 & 822.4 & 5.618 & 1.838 & 4 & 6 & 1.87\end{array}$

$\begin{array}{lllllllll}\mathrm{SnS} & 4 & 2 & 487.7 & 3.537 & 2.240 & 4 & 6 & 1.92\end{array}$

$\begin{array}{lllllllll}\mathrm{SnSe} & 4 & 3 & 332.0 & 3.079 & 2.370 & 4 & 6 & 1.92\end{array}$

$\begin{array}{lllllllll}\mathrm{SnTe} & 4 & 4 & 259.5 & 2.440 & 2.570 & 4 & 6 & 1.85\end{array}$

$\begin{array}{lllllllll}\mathrm{PbO} & 5 & 1 & 721.8 & 4.559 & 2.010 & 4 & 6 & 1.89\end{array}$

$\begin{array}{lllllllll}\mathrm{PbS} & 5 & 2 & 428.1 & 2.998 & 2.395 & 4 & 6 & 1.92\end{array}$

$\begin{array}{lllllllll}\mathrm{PbSe} & 5 & 3 & 277.4 & 2.592 & 2.530 & 4 & 6 & 1.90\end{array}$

$\begin{array}{lllllllll}\text { PbTe } & 5 & 4 & 211.8 & 2.087 & 2.730 & 4 & 6 & 1.84\end{array}$

$\begin{array}{lllllllll}\mathrm{NO}^{+} & 1 & 1 & 2376.4 & 24.842 & 1.063 & 5 & 5 & 2.11\end{array}$

$\begin{array}{lllllllll}\mathrm{N}_{2} & 1 & 1 & 2359.6 & 22.979 & 1.095 & 5 & 5 & 2.10\end{array}$

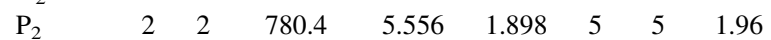

$\begin{array}{lllllllll}\mathrm{PN} & 2 & 1 & 1337.2 & 10.160 & 1.490 & 5 & 5 & 1.98\end{array}$

$\begin{array}{lllllllll}\mathrm{As}_{2} & 3 & 3 & 429.6 & 4.077 & 2.103 & 5 & 5 & 1.85\end{array}$

$\begin{array}{lllllllll}\text { AsN } & 3 & 1 & 1068.5 & 7.937 & 1.618 & 5 & 5 & 1.89\end{array}$

$\begin{array}{lllllllll}\mathrm{AsP} & 3 & 2 & 604.0 & 4.715 & 1.999 & 5 & 5 & 1.89\end{array}$

$\begin{array}{lllllllll}\mathrm{NS}^{+} & 3 & 2 & 1415.0 & 11.488 & 1.440 & 5 & 5 & 2.06\end{array}$

$\begin{array}{lllllllll}\mathrm{SbBi} & 4 & 5 & 220.0 & 2.194 & 2.730 & 5 & 5 & 1.90\end{array}$

$\begin{array}{lllllllll}\mathrm{Sb}_{2} & 4 & 4 & 270.0 & 2.617 & 2.342 & 5 & 5 & 1.55\end{array}$

$\begin{array}{lllllllll}\mathrm{SbP} & 4 & 2 & 500.1 & 3.633 & 2.205 & 5 & 5 & 1.86\end{array}$

$\begin{array}{lllllllll}\mathrm{Bi}_{2} & 5 & 5 & 172.7 & 1.837 & 2.660 & 5 & 5 & 1.49\end{array}$ 
Table 1 (continued)

\begin{tabular}{|c|c|c|c|c|c|c|c|c|}
\hline Species & & & $\omega_{\mathrm{e}}$ & $k_{\mathrm{e}}$ & $r_{\mathrm{e}}$ & $z_{1}$ & $z_{2}$ & $n$ \\
\hline $\mathrm{CCl}$ & 1 & 2 & 843.6 & 3.759 & 1.730 & 4 & 7 & 1.00 \\
\hline $\mathrm{SiF}$ & 2 & 1 & 856.7 & 4.901 & 1.603 & 4 & 7 & 1.08 \\
\hline $\mathrm{SiCl}$ & 2 & 2 & 535.4 & 2.647 & 2.000 & 4 & 7 & 1.01 \\
\hline $\mathrm{SiBr}$ & 2 & 3 & 425.4 & 2.216 & 2.150 & 4 & 7 & 1.01 \\
\hline SiI & 2 & 4 & 363.8 & 1.788 & 2.450 & 4 & 7 & 1.12 \\
\hline $\mathrm{GeF}$ & 3 & 1 & 665.7 & 3.946 & 1.745 & 4 & 7 & 1.07 \\
\hline $\mathrm{GeCl}$ & 3 & 2 & 408.4 & 2.341 & 2.080 & 4 & 7 & 0.98 \\
\hline $\mathrm{GeBr}$ & 3 & 3 & 296.6 & 1.971 & 2.290 & 4 & 7 & 1.04 \\
\hline $\mathrm{SnF}$ & 4 & 1 & 585.3 & 3.306 & 1.820 & 4 & 7 & 1.00 \\
\hline $\mathrm{SnCl}$ & 4 & 2 & 352.4 & 1.997 & 2.320 & 4 & 7 & 1.09 \\
\hline $\mathrm{SnBr}$ & 4 & 3 & 247.7 & 1.726 & 2.440 & 4 & 7 & 1.07 \\
\hline $\mathrm{PbF}$ & 5 & 1 & 507.2 & 2.638 & 2.010 & 4 & 7 & 1.01 \\
\hline $\mathrm{PbCl}$ & 5 & 2 & 303.9 & 1.647 & 2.430 & 4 & 7 & 1.01 \\
\hline $\mathrm{PbBr}$ & 5 & 3 & 207.5 & 1.463 & 2.600 & 4 & 7 & 1.06 \\
\hline NO & 1 & 1 & 1904.0 & 15.949 & 1.151 & 5 & 6 & 1.50 \\
\hline $\mathrm{PF}^{+}$ & 2 & 1 & 846.8 & 4.974 & 1.500 & 5 & 6 & 0.90 \\
\hline $\mathrm{PO}$ & 2 & 1 & 1233.3 & 9.453 & 1.476 & 5 & 6 & 1.64 \\
\hline PS & 2 & 2 & 739.1 & 5.064 & 1.900 & 5 & 6 & 1.64 \\
\hline $\mathrm{AsO}$ & 3 & 1 & 967.1 & 7.266 & 1.624 & 5 & 6 & 1.60 \\
\hline $\mathrm{AsO}^{+}$ & 3 & 1 & 1091.3 & 9.253 & 1.568 & 5 & 6 & 1.87 \\
\hline $\mathrm{AsS}^{+}$ & 3 & 2 & 644.3 & 5.485 & 1.945 & 5 & 6 & 1.88 \\
\hline NS & 1 & 2 & 1218.7 & 8.522 & 1.494 & 5 & 6 & 1.53 \\
\hline $\mathrm{NSe}$ & 1 & 3 & 956.8 & 6.427 & 1.652 & 5 & 6 & 1.47 \\
\hline $\mathrm{SbO}$ & 4 & 1 & 816.0 & 5.542 & 1.826 & 5 & 6 & 1.62 \\
\hline $\mathrm{BiO}$ & 5 & 1 & 692.4 & 4.198 & 1.934 & 5 & 6 & 1.42 \\
\hline $\mathrm{BiS}$ & 5 & 2 & 408.7 & 2.731 & 2.319 & 5 & 6 & 1.44 \\
\hline $\mathrm{O}_{2}^{+}$ & 1 & 1 & 1904.8 & 17.095 & 1.116 & 5 & 6 & 1.49 \\
\hline $\mathrm{SO}^{+}$ & 2 & 1 & 1360.0 & 11.618 & 1.424 & 5 & 6 & 1.85 \\
\hline $\mathrm{S}_{2}^{+}$ & 2 & 2 & 790.0 & 5.878 & 1.825 & 5 & 6 & 1.72 \\
\hline $\mathrm{NO}^{-}$ & 1 & 1 & 1363.0 & 8.172 & 1.258 & 5 & 7 & 0.89 \\
\hline $\mathrm{NF}$ & 1 & 1 & 1141.4 & 6.187 & 1.316 & 5 & 7 & 0.75 \\
\hline $\mathrm{NCl}$ & 1 & 2 & 827.0 & 4.029 & 1.614 & 5 & 7 & 0.81 \\
\hline $\mathrm{NBr}$ & 1 & 3 & 691.8 & 3.353 & 1.787 & 5 & 7 & 0.86 \\
\hline $\mathrm{PF}$ & 2 & 1 & 846.8 & 4.974 & 1.589 & 5 & 7 & 0.96 \\
\hline $\mathrm{AsF}$ & 3 & 1 & 685.8 & 4.201 & 1.736 & 5 & 7 & 1.01 \\
\hline $\mathrm{SbF}$ & 4 & 1 & 605.0 & 3.541 & 1.918 & 5 & 7 & 1.08 \\
\hline $\mathrm{BiF}$ & 5 & 1 & 510.7 & 2.676 & 1.810 & 5 & 7 & 0.71 \\
\hline $\mathrm{BiCl}$ & 5 & 2 & 307.7 & 1.691 & 2.480 & 5 & 7 & 0.97 \\
\hline $\mathrm{BiBr}$ & 5 & 3 & 209.3 & 1.492 & 2.630 & 5 & 7 & 0.99 \\
\hline BiI & 5 & 4 & 163.9 & 1.250 & 2.790 & 5 & 7 & 0.96 \\
\hline $\mathrm{SeF}$ & 3 & 1 & 757.0 & 5.182 & 1.741 & 6 & 7 & 1.14 \\
\hline $\mathrm{F}_{2}^{+}$ & 1 & 1 & 1073.3 & 6.448 & 1.322 & 7 & 6 & 0.72 \\
\hline IO & 4 & 1 & 681.5 & 3.887 & 1.868 & 7 & 6 & 1.02 \\
\hline $\mathrm{F}_{2}$ & 1 & 1 & 916.6 & 4.703 & 1.412 & 7 & 7 & 0.57 \\
\hline $\mathrm{Cl}_{2}$ & 2 & 2 & 564.9 & 3.333 & 1.989 & 7 & 7 & 0.94 \\
\hline $\mathrm{BrCl}$ & 3 & 2 & 430.0 & 2.675 & 2.140 & 7 & 7 & 0.91 \\
\hline $\mathrm{Br}_{2}$ & 3 & 3 & 323.2 & 2.459 & 2.284 & 7 & 7 & 0.98 \\
\hline $\mathrm{BrF}$ & 3 & 1 & 670.8 & 4.060 & 1.759 & 7 & 7 & 0.85 \\
\hline IF & 4 & 1 & 610.2 & 3.625 & 1.909 & 7 & 7 & 0.93 \\
\hline $\mathrm{ICl}$ & 4 & 2 & 384.2 & 2.410 & 2.320 & 7 & 7 & 1.00 \\
\hline $\mathrm{IBr}$ & 4 & 3 & 268.4 & 2.081 & 2.480 & 7 & 7 & 1.01 \\
\hline $\mathrm{I}_{2}$ & 4 & 4 & 214.4 & 1.718 & 2.667 & 7 & 7 & 1.00 \\
\hline
\end{tabular}

Table 1 (continued)

\begin{tabular}{|c|c|c|c|c|c|c|c|c|}
\hline Species & & & $\omega_{\mathrm{e}}$ & $k_{\mathrm{e}}$ & $r_{\mathrm{e}}$ & $z_{1}$ & $z_{2}$ & $n$ \\
\hline $\mathrm{F}_{2}^{-}$ & 1 & 1 & 510.0 & 1.456 & 1.880 & 7 & 8 & 0.34 \\
\hline $\mathrm{Ne}_{2}^{+}$ & 1 & 1 & 510.0 & 1.532 & 1.750 & 7 & 8 & 0.30 \\
\hline
\end{tabular}

Columns 2 and 3 identify the period of the periodic table to which each atom in the diatomic molecule belongs. The vibrational frequencies $\left(\omega_{\mathrm{e}}\right)$ are in $\mathrm{cm}^{-1}$ and the force constants $\left(k_{\mathrm{e}}\right)$ in mdyne/ $\AA$. The internuclear distances are in $\AA$, while $z_{1}$ and $z_{2}$ are the number of valence electrons from atoms 1 and 2. Most of the vibrational frequencies, force constants and internuclear distances are from Refs. [56,57].

orders for over 150 diatomic molecules using the parameters obtained by Guggenheimer for covalently bonded molecules $(C=2.738$ and $s=2.46)$. We have included all those molecules reported by Guggenheimer, but have also added many from more recent sources. The table is sorted according to the values of $z_{1}$ and $z_{2}$, and spaces have been inserted to help examine various groups with similar values of bond order. For example the first group (with $z_{1}=1$ ) includes $\mathrm{H}_{2}$, as well as dimers of the alkali metals and hydrides of the first row of the periodic table. All of these molecules are formed from at least one atom with $s^{1}$ configurations and would be expected to have single bonds. The calculated values for experimental bond order are all quite close to one. Note that the same is true for almost all diatomic molecules for which one of the atoms has $z=7$, i.e. halogens. For molecules in which we might expect formal double bonds (such as those for which $z_{1}, z_{2}=4,4$ or 5,6) we find experimental bond orders mostly above 1.4 but below 1.9. For molecules in which we expect formal triple bonds (such as those for which $z_{1}, z_{2}=4,5$ or 5,5 or 4,6 ) we find experimental bond orders greater than 1.8 , the highest being 2.15 for $\mathrm{N}_{2}^{+}$. \{ Note that here and in other tables we have included several ionic species. In order to select an appropriate value of $z_{1}$ or $z_{2}$, for cations we have subtracted 1 from the neutral $\mathrm{z}$, and for anions we have added 1 . To prevent division by zero, we have chosen a more reasonable value of 8 where needed, as for alkali metal ions such as $\left.\mathrm{Na}^{+}\right\}$. The range of species for which these results are consistent with expectations is remarkable. The major exceptions are for the series 
Table 2

Bond orders for diatomic molecules using Eq. (14), with $C=2.491$ and $s=1.84$. Included are polar molecules, most hydrides, and certain triplet ground state molecules

\begin{tabular}{|c|c|c|c|c|c|c|c|c|}
\hline \multicolumn{3}{|l|}{ Species } & \multirow{2}{*}{$\frac{\omega_{\mathrm{e}}}{1406.0}$} & \multirow{2}{*}{$\begin{array}{l}k_{\mathrm{e}} \\
1.027\end{array}$} & \multirow{2}{*}{$\begin{array}{l}r_{\mathrm{e}} \\
1.60\end{array}$} & \multirow{2}{*}{$\begin{array}{l}z_{1} \\
1\end{array}$} & \multirow[t]{2}{*}{$z_{2}$} & \multirow{2}{*}{$\begin{array}{l}n \\
0.97\end{array}$} \\
\hline $\mathrm{HLi}$ & 0 & 1 & & & & & & \\
\hline $\mathrm{HNa}$ & 0 & 2 & 1170.8 & 0.781 & 1.89 & 1 & 1 & 1.01 \\
\hline HK & 0 & 3 & 983.3 & 0.561 & 2.24 & 1 & 1 & 1.00 \\
\hline $\mathrm{HRb}$ & 0 & 4 & 936.0 & 0.515 & 2.37 & 1 & 1 & 1.01 \\
\hline $\mathrm{HCs}$ & 0 & 5 & 890.7 & 0.469 & 2.49 & 1 & 1 & 1.01 \\
\hline $\mathrm{HBe}$ & 0 & 1 & 2058.0 & 2.266 & 1.34 & 1 & 2 & 1.11 \\
\hline $\mathrm{HMg}$ & 0 & 2 & 1495.0 & 1.277 & 1.73 & 1 & 2 & 0.99 \\
\hline $\mathrm{HCa}$ & 0 & 3 & 1299.0 & 0.979 & 2.00 & 1 & 2 & 1.00 \\
\hline $\mathrm{HZn}$ & 0 & 3 & 1608.0 & 1.515 & 1.60 & 1 & 2 & 1.02 \\
\hline $\mathrm{HSr}$ & 0 & 4 & 1207.0 & 0.857 & 2.15 & 1 & 2 & 0.99 \\
\hline $\mathrm{HCd}$ & 0 & 4 & 1431.0 & 1.208 & 1.76 & 1 & 2 & 0.97 \\
\hline $\mathrm{HBa}$ & 0 & 5 & 1172.0 & 0.811 & 2.23 & 1 & 2 & 1.01 \\
\hline $\mathrm{HHg}$ & 0 & 5 & 1387.0 & 1.139 & 1.74 & 1 & 2 & 0.90 \\
\hline $\mathrm{HMg}$ & 0 & 2 & 1495.2 & 1.274 & 1.73 & 1 & 2 & 0.99 \\
\hline HAl & 0 & 2 & 1683.0 & 1.625 & 1.65 & 1 & 3 & 0.94 \\
\hline $\mathrm{HCo}$ & 0 & 3 & 1890.0 & 2.090 & 1.54 & 1 & 3 & 1.08 \\
\hline $\mathrm{HNi}$ & 0 & 3 & 1927.0 & 2.172 & 1.48 & 1 & 3 & 1.03 \\
\hline $\mathrm{HCu}$ & 0 & 3 & 1940.0 & 2.205 & 1.46 & 1 & 3 & 1.03 \\
\hline HAg & 0 & 4 & 1760.0 & 1.826 & 1.62 & 1 & 3 & 1.03 \\
\hline HTl & 0 & 5 & 1391.0 & 1.146 & 1.87 & 1 & 3 & 0.84 \\
\hline $\mathrm{HGa}$ & 0 & 3 & 1604.3 & 1.506 & 1.66 & 1 & 3 & 0.89 \\
\hline H In & 0 & 4 & 1476.0 & 1.282 & 1.84 & 1 & 3 & 0.91 \\
\hline HMn & 0 & 3 & 1548.0 & 1.397 & 1.73 & 1 & 3 & 0.89 \\
\hline $\mathrm{HSi}$ & 0 & 2 & 2080.0 & 2.485 & 1.52 & 1 & 4 & 1.08 \\
\hline $\mathrm{HPb}$ & 0 & 5 & 1565.0 & 1.450 & 1.84 & 1 & 4 & 0.89 \\
\hline HP & 0 & 2 & 2380.0 & 3.264 & 1.43 & 1 & 5 & 1.14 \\
\hline $\mathrm{HBi}$ & 0 & 5 & 1699.0 & 1.710 & 1.81 & 1 & 5 & 0.91 \\
\hline HAs & 0 & 3 & 2130.0 & 2.638 & 1.53 & 1 & 5 & 1.04 \\
\hline HSe & 0 & 3 & 2400.0 & 3.377 & 1.48 & 1 & 6 & 1.13 \\
\hline $\mathrm{HGe}$ & 0 & 3 & 1833.8 & 1.969 & 1.59 & 1 & 6 & 0.76 \\
\hline HI & 0 & 4 & 2309.5 & 3.149 & 1.60 & 1 & 7 & 1.14 \\
\hline $\mathrm{HCl}$ & 0 & 2 & 2989.7 & 5.161 & 1.28 & 1 & 7 & 1.22 \\
\hline $\mathrm{HBr}$ & 0 & 3 & 2649.7 & 4.118 & 1.41 & 1 & 7 & 1.18 \\
\hline HAu & 0 & 5 & 2306.0 & 3.148 & 1.52 & 1 & 7 & 1.04 \\
\hline HLu & 0 & 5 & 1520.0 & 1.361 & 1.91 & 1 & 7 & 0.68 \\
\hline $\mathrm{HPt}$ & 0 & 5 & 2294.7 & 3.112 & 1.53 & 1 & 7 & 1.03 \\
\hline $\mathrm{LiBr}$ & 1 & 3 & 563.2 & 1.203 & 2.17 & 1 & 7 & 0.76 \\
\hline $\mathrm{LiCl}$ & 1 & 2 & 643.3 & 1.425 & 2.02 & 1 & 7 & 0.79 \\
\hline $\mathrm{LiF}$ & 1 & 1 & 910.3 & 2.502 & 1.56 & 1 & 7 & 0.86 \\
\hline LiI & 1 & 4 & 498.2 & 0.972 & 2.39 & 1 & 7 & 0.73 \\
\hline $\mathrm{NaF}$ & 2 & 1 & 536.0 & 1.760 & 1.93 & 1 & 7 & 0.89 \\
\hline $\mathrm{NaCl}$ & 2 & 2 & 380.0 & 1.186 & 2.51 & 1 & 7 & 0.98 \\
\hline $\mathrm{NaBr}$ & 2 & 3 & 315.0 & 1.044 & 2.64 & 1 & 7 & 0.94 \\
\hline $\mathrm{NaI}$ & 2 & 4 & 286.0 & 0.938 & 2.90 & 1 & 7 & 1.01 \\
\hline $\mathrm{KCl}$ & 3 & 2 & 280.0 & 0.859 & 2.79 & 1 & 7 & 0.86 \\
\hline $\mathrm{KBr}$ & 3 & 3 & 231.0 & 0.825 & 2.94 & 1 & 7 & 0.91 \\
\hline KI & 3 & 4 & 212.0 & 0.792 & 3.23 & 1 & 7 & 1.04 \\
\hline $\mathrm{KF}$ & 3 & 1 & 428.0 & 1.378 & 2.17 & 1 & 7 & 0.87 \\
\hline $\mathrm{RbCl}$ & 4 & 2 & 228.0 & 0.759 & 2.79 & 1 & 7 & 0.76 \\
\hline $\mathrm{RbF}$ & 4 & 1 & 376.0 & 1.293 & 2.27 & 1 & 7 & 0.89 \\
\hline RbI & 4 & 4 & 138.5 & 0.575 & 3.18 & 1 & 7 & 0.73 \\
\hline
\end{tabular}

Table 2 (continued)

\begin{tabular}{|c|c|c|c|c|c|c|c|c|}
\hline \multicolumn{3}{|l|}{ Species } & \multirow{2}{*}{$\frac{\omega_{\mathrm{e}}}{352.6}$} & \multirow{2}{*}{$\begin{array}{l}k_{\mathrm{e}} \\
1.218\end{array}$} & \multirow{2}{*}{$\begin{array}{l}r_{\mathrm{e}} \\
2.35\end{array}$} & \multirow{2}{*}{$\frac{z_{1}}{1}$} & \multirow{2}{*}{$\frac{z_{2}}{7}$} & \multirow{2}{*}{$\begin{array}{l}n \\
0.89\end{array}$} \\
\hline CsF & 5 & 1 & & & & & & \\
\hline $\mathrm{BeO}$ & 1 & 1 & 1487.3 & 7.507 & 1.331 & 2 & 6 & 1.47 \\
\hline $\mathrm{BeS}$ & 1 & 2 & 997.9 & 4.125 & 1.742 & 2 & 6 & 1.33 \\
\hline $\mathrm{MgO}$ & 2 & 1 & 785.1 & 3.484 & 1.749 & 2 & 6 & 1.13 \\
\hline $\mathrm{MgS}$ & 2 & 2 & 528.7 & 2.257 & 2.143 & 2 & 6 & 1.06 \\
\hline $\mathrm{CaO}$ & 3 & 1 & 732.1 & 3.609 & 1.822 & 2 & 6 & 1.26 \\
\hline $\mathrm{CaS}$ & 3 & 2 & 462.2 & 2.236 & 2.318 & 2 & 6 & 1.22 \\
\hline $\mathrm{SrO}$ & 4 & 1 & 653.5 & 3.405 & 1.919 & 2 & 6 & 1.31 \\
\hline $\mathrm{SrS}$ & 4 & 2 & 388.4 & 2.084 & 2.440 & 2 & 6 & 1.25 \\
\hline $\mathrm{BaO}$ & 5 & 1 & 669.8 & 3.788 & 1.940 & 2 & 6 & 1.49 \\
\hline $\mathrm{BaS}$ & 5 & 2 & 379.4 & 2.201 & 2.507 & 2 & 6 & 1.38 \\
\hline $\mathrm{BeF}$ & 1 & 1 & 1266.0 & 5.772 & 1.36 & 2 & 7 & 1.09 \\
\hline $\mathrm{BeBr}$ & 1 & 3 & 715.0 & 2.434 & 1.95 & 2 & 7 & 0.89 \\
\hline $\mathrm{BeCl}$ & 1 & 2 & 846.7 & 3.026 & 1.80 & 2 & 7 & 0.95 \\
\hline $\mathrm{MgCl}$ & 2 & 2 & 466.0 & 1.845 & 2.51 & 2 & 7 & 1.08 \\
\hline $\mathrm{MgBr}$ & 2 & 3 & 373.2 & 1.530 & 2.64 & 2 & 7 & 0.98 \\
\hline $\mathrm{MgF}$ & 2 & 1 & 711.7 & 3.163 & 1.75 & 2 & 7 & 0.95 \\
\hline $\mathrm{CaF}$ & 3 & 1 & 587.3 & 2.619 & 2.02 & 2 & 7 & 1.02 \\
\hline $\mathrm{CuF}$ & 3 & 1 & 619.5 & 3.307 & 1.76 & 2 & 7 & 1.00 \\
\hline $\mathrm{CaCl}$ & 3 & 2 & 364.5 & 1.473 & 2.79 & 2 & 7 & 1.04 \\
\hline $\mathrm{CuCl}$ & 3 & 2 & 417.0 & 2.331 & 2.13 & 2 & 7 & 1.01 \\
\hline $\mathrm{CaBr}$ & 3 & 3 & 280.2 & 1.235 & 2.94 & 2 & 7 & 0.96 \\
\hline $\mathrm{CuBr}$ & 3 & 3 & 314.1 & 2.058 & 2.25 & 2 & 7 & 0.98 \\
\hline $\mathrm{CuI}$ & 3 & 4 & 264.8 & 1.749 & 2.40 & 2 & 7 & 0.94 \\
\hline $\mathrm{SrF}$ & 4 & 1 & 500.1 & 2.301 & 2.15 & 2 & 7 & 1.01 \\
\hline $\mathrm{SrCl}$ & 4 & 2 & 301.1 & 1.348 & 2.79 & 2 & 7 & 0.96 \\
\hline $\mathrm{SrBr}$ & 4 & 3 & 212.0 & 1.107 & 2.94 & 2 & 7 & 0.86 \\
\hline $\mathrm{BaF}$ & 5 & 1 & 468.9 & 2.162 & 2.23 & 2 & 7 & 1.01 \\
\hline $\mathrm{BaCl}$ & 5 & 2 & 279.2 & 1.294 & 2.79 & 2 & 7 & 0.92 \\
\hline $\mathrm{BaBr}$ & 5 & 3 & 192.0 & 1.097 & 2.94 & 2 & 7 & 0.86 \\
\hline $\mathrm{BF}$ & 1 & 1 & 1402.1 & 8.069 & 1.26 & 3 & 7 & 1.09 \\
\hline $\mathrm{LaF}$ & 3 & 1 & 570.0 & 3.199 & 2.03 & 3 & 7 & 1.03 \\
\hline $\mathrm{ScF}$ & 3 & 1 & 735.6 & 4.257 & 1.79 & 3 & 7 & 1.09 \\
\hline $\mathrm{TIF}$ & 5 & 1 & 477.3 & 2.334 & 2.08 & 3 & 7 & 0.79 \\
\hline SiI & 2 & 4 & 363.8 & 1.788 & 2.45 & 4 & 7 & 0.71 \\
\hline $\mathrm{GeF}$ & 3 & 1 & 665.7 & 3.946 & 1.75 & 4 & 7 & 0.83 \\
\hline $\mathrm{SnCl}$ & 4 & 2 & 351.1 & 1.966 & 2.36 & 4 & 7 & 0.72 \\
\hline $\mathrm{SnF}$ & 4 & 1 & 577.6 & 3.216 & 1.94 & 4 & 7 & 0.83 \\
\hline $\mathrm{YCl}$ & 4 & 1 & 380.7 & 2.143 & 2.41 & 4 & 7 & 0.82 \\
\hline YF & 4 & 1 & 631.3 & 3.675 & 1.93 & 4 & 7 & 0.93 \\
\hline AsF & 3 & 1 & 685.8 & 4.201 & 1.74 & 5 & 7 & 0.79 \\
\hline $\mathrm{SeF}$ & 3 & 1 & 757.0 & 5.182 & 1.74 & 6 & 7 & 0.89 \\
\hline $\mathrm{SbF}$ & 4 & 1 & 605.0 & 3.541 & 1.92 & 5 & 7 & 0.80 \\
\hline LuF & 5 & 1 & 611.8 & 3.779 & 1.92 & 7 & 7 & 0.72 \\
\hline $\mathrm{O}_{2}$ & 1 & 1 & 1580.0 & 11.767 & 1.21 & 6 & 6 & 1.11 \\
\hline SO & 2 & 1 & 1123.7 & 7.941 & 1.49 & 6 & 6 & 1.11 \\
\hline $\mathrm{S}_{2}$ & 2 & 2 & 725.8 & 4.975 & 1.89 & 6 & 6 & 1.07 \\
\hline $\mathrm{S} \mathrm{Se}$ & 2 & 3 & 555.6 & 4.123 & 2.04 & 6 & 6 & 1.02 \\
\hline $\mathrm{SeO}$ & 3 & 1 & 908.9 & 6.476 & 1.61 & 6 & 6 & 1.04 \\
\hline $\mathrm{Se}_{2}$ & 3 & 3 & 392.5 & 3.584 & 2.16 & 6 & 6 & 0.99 \\
\hline $\mathrm{TeO}$ & 4 & 1 & 796.1 & 5.309 & 1.82 & 6 & 6 & 1.07 \\
\hline
\end{tabular}


Table 2 (continued)

\begin{tabular}{|c|c|c|c|c|c|c|c|c|}
\hline \multicolumn{3}{|l|}{ Species } & \multirow{2}{*}{$\frac{\omega_{\mathrm{e}}}{471.2}$} & \multirow{2}{*}{$\begin{array}{l}k_{\mathrm{e}} \\
3.356\end{array}$} & \multirow{2}{*}{$\frac{r_{\mathrm{e}}}{2.23}$} & \multirow{2}{*}{$\frac{z_{1}}{6}$} & \multirow{2}{*}{$\frac{z_{2}}{6}$} & \multirow{2}{*}{$\begin{array}{l}n \\
0.98\end{array}$} \\
\hline $\mathrm{TeS}$ & 4 & 2 & & & & & & \\
\hline TeSe & 4 & 3 & 316.2 & 2.853 & 2.37 & 6 & 6 & 0.94 \\
\hline $\mathrm{Te}_{2}$ & 4 & 4 & 251.5 & 2.378 & 2.59 & 6 & 6 & 0.92 \\
\hline $\mathrm{XeCl}$ & 4 & 2 & 26.3 & 0.011 & 3.180 & 8 & 7 & 0.005 \\
\hline $\mathrm{Ne}_{2}$ & 1 & 1 & 13.7 & 0.001 & 3.150 & 8 & 8 & 0.0005 \\
\hline $\mathrm{NeAr}$ & 1 & 2 & 20.9 & 0.003 & 3.430 & 8 & 8 & 0.002 \\
\hline $\mathrm{NeKr}$ & 1 & 3 & 18.7 & 0.003 & 3.580 & 8 & 8 & 0.002 \\
\hline $\mathrm{Ar}_{2}$ & 2 & 2 & 25.7 & 0.008 & 3.758 & 8 & 8 & 0.004 \\
\hline $\mathrm{Xe}_{2}$ & 4 & 4 & 21.1 & 0.017 & 4.361 & 8 & 8 & 0.013 \\
\hline
\end{tabular}

Columns 2 and 3 identify the period of the periodic table to which each atom in the diatomic molecule belongs. The vibrational frequencies $\left(\omega_{\mathrm{e}}\right)$ are in $\mathrm{cm}^{-1}$ and the force constants $\left(k_{\mathrm{e}}\right)$ in mdyne/A. The internuclear distances are in $\AA$, while $z_{1}$ and $z_{2}$ are the number of valence electrons from atoms 1 and 2. Most of the vibrational frequencies, force constants and internuclear distances are from Refs. [56,57].

$\mathrm{F}_{2}^{+}(n=0.72) \mathrm{F}_{2}(n=0.57)$ and $\mathrm{F}_{2}^{-}(n=0.34)$. These are all considerably lower than the formal bond order for each of these, which are 1.5, 1 and 0.5, respectively. Furthermore, the value for $\mathrm{F}_{2}$ is considerably lower than those for $\mathrm{Cl}_{2}, \mathrm{Br}_{2}$ and $\mathrm{I}_{2}$ ( $n=0.94,0.98$ and 1.00, respectively). Flourine is well known to have anomalous properties $[44,45]$ due to its exceptionally small size, causing increased repulsive forces relative to those of attraction in molecules. These effects might be expected then to result in lower bond order. Note also that $\mathrm{F}_{2}^{-}$is isoelectronic with $\mathrm{Ne}_{2}^{+}$which has an experimental bond order of 0.30 , compared with a formal bond order of 0.5 .

In Table 2 we have calculated the bond orders for over 100 diatomic molecules using the parameters obtained by Guggenheimer for noble gas, ionic and certain hydride molecules $(C=2.491$ and $s=1.84)$. We have included all those molecules reported by Guggenheimer, but have also added many from more recent sources. As mentioned above, most of these molecules coincide with those for which Bader and Essen [26] found $\nabla^{2} \rho\left(r_{\mathrm{c}}\right)>0$. The major exceptions are for $\mathrm{C}_{2}$ (for which $\nabla^{2} \rho\left(r_{\mathrm{c}}\right)<0$ ), which we have transferred to Table 1 , and the ionic molecules such as $\mathrm{MgO}$ (for which $\nabla^{2} \rho\left(r_{\mathrm{c}}\right)>0, z_{1}, z_{2}=2,6$ ), which we have included in Table 2 in order to be consistent with
Table 3

Bond orders for transition metal diatomic molecules using Eq. (14), with $C=2.738$ and $s=2.46$

\begin{tabular}{|c|c|c|c|c|c|}
\hline Species & $k_{\mathrm{e}}$ & $r_{\mathrm{e}}$ & $z_{1}$ & $z_{2}$ & $n$ \\
\hline $\mathrm{Ti}_{2}$ & 2.348 & 1.94 & 3 & 3 & 1.46 \\
\hline $\mathrm{V}_{2}$ & 4.326 & 1.77 & 3 & 3 & 2.15 \\
\hline $\mathrm{Cr}_{2}$ & 3.538 & 1.70 & 3 & 3 & 1.58 \\
\hline $\mathrm{Mn}_{2}$ & 0.094 & 3.40 & 3 & 3 & 0.23 \\
\hline $\mathrm{Fe}_{2}$ & 1.476 & 2.02 & 3 & 3 & 1.01 \\
\hline $\mathrm{Ni}_{2}$ & 1.162 & 2.15 & 3 & 3 & 0.93 \\
\hline $\mathrm{Cu}_{2}$ & 1.329 & 2.22 & 3 & 3 & 1.15 \\
\hline $\mathrm{Zn}_{2}$ & 0.013 & 4.19 & 3 & 3 & 0.05 \\
\hline $\mathrm{Zr}_{2}$ & 2.511 & 2.24 & 4 & 4 & 1.67 \\
\hline $\mathrm{Nb}_{2}$ & 4.84 & 2.08 & 4 & 4 & 2.67 \\
\hline $\mathrm{Mo}_{2}$ & 6.33 & 1.93 & 4 & 4 & 2.91 \\
\hline $\mathrm{Ag}_{2}$ & 1.176 & 2.53 & 4 & 4 & 1.05 \\
\hline $\mathrm{Cd}_{2}$ & 0.017 & 4.07 & 4 & 4 & 0.05 \\
\hline $\mathrm{Pt}_{2}$ & 2.85 & 2.33 & 7 & 7 & 1.19 \\
\hline $\mathrm{Au}_{2}$ & 2.115 & 2.47 & 7 & 7 & 1.02 \\
\hline $\mathrm{Hg}_{2}$ & 0.02 & 3.63 & 7 & 7 & 0.02 \\
\hline $\mathrm{AgAu}$ & 1.6149 & 2.50 & 4 & 7 & 1.06 \\
\hline $\mathrm{CuAu}$ & 1.7468 & 2.33 & 3 & 7 & 1.12 \\
\hline $\mathrm{CuAg}$ & 1.2377 & 2.37 & 3 & 4 & 1.09 \\
\hline $\mathrm{PtCu}$ & 2.3456 & 2.34 & 7 & 3 & 1.51 \\
\hline $\mathrm{NiCu}$ & 1.3398 & 2.23 & 3 & 3 & 1.18 \\
\hline $\mathrm{VNb}$ & 4.406 & 1.95 & 3 & 4 & 2.39 \\
\hline $\mathrm{VCr}$ & 4.0976 & 1.73 & 3 & 3 & 1.91 \\
\hline $\mathrm{ZrCo}$ & 2.6981 & 1.99 & 4 & 3 & 1.54 \\
\hline $\mathrm{YCu}$ & 0.8151 & 2.62 & 4 & 3 & 0.92 \\
\hline
\end{tabular}

Vibrational frequencies $\left(\omega_{\mathrm{e}}\right)$ are in $\mathrm{cm}^{-1}$ and force constants $\left(\mathrm{k}_{\mathrm{e}}\right)$ in mdyne/Å. Internuclear distances are in $\AA$, while $z_{1}$ and $z_{2}$ are the number of valence electrons from atoms 1 and 2. Most of the vibrational frequencies, force constants and internuclear distances are from: Refs. [4,33,34] and for $\{\mathrm{YCu}\}$ from Ref. [58], for $\{\mathrm{ZrCo}\}$ from Ref. [59], for $\{\mathrm{AgAu}\}$ from Ref. [60], for $\{\mathrm{CuAu}\}$ from Ref. [61], for $\{\mathrm{CuAu}\}$ from Ref. [62], for $\{\mathrm{PtCu}\}$ from Ref. [63], for \{VCr $\}$ from Ref. [64], for $\{\mathrm{NiCu}\}$ from Ref. [65], for $\{\mathrm{VCr}, \mathrm{VNb}\}$ from Ref. [66].

more modern calculations. However, following Guggenheimer, we have left in Table 2 the molecules for which $z_{1}, z_{2}=6,6$ (such as $\mathrm{O}_{2}, \mathrm{SO}, \mathrm{S}_{2}$ ). These molecules all have a triplet ground state. We then expect a reduction of total electron density between the nuclei resulting in a formal single bond [46], and this is consistent with the experimental bond orders obtained. In Table 2, the polar hydrides and the alkali halides, all with formal bond orders of 1 , have an experimental bond order close to one. The same is true for most of the other metallic halides $\left(z_{2}=7\right)$, while 
Table 4

Bond orders for diatomic molecules formed from a transition metal atom and an atom from elsewhere in the periodic table, using Eq. (14), with $C=2.738$ and $s=2.46$

\begin{tabular}{|c|c|c|c|c|c|c|c|c|}
\hline Species & & & $\omega_{\mathrm{e}}$ & $k_{\mathrm{e}}$ & $r_{\mathrm{e}}$ & $z_{1}$ & $z_{2}$ & $n$ \\
\hline $\mathrm{AgAl}$ & 4 & 2 & 254.3 & 0.823 & 2.473 & 4 & 3 & 0.80 \\
\hline $\mathrm{AgBi}$ & 4 & 5 & 152.1 & 0.971 & 3.450 & 4 & 5 & 1.67 \\
\hline $\mathrm{AgBr}$ & 4 & 3 & 247.7 & 1.673 & 2.393 & 4 & 7 & 0.99 \\
\hline $\mathrm{AgCl}$ & 4 & 2 & 343.5 & 1.838 & 2.281 & 4 & 7 & 0.96 \\
\hline $\mathrm{AgF}$ & 4 & 1 & 513.4 & 2.506 & 1.983 & 4 & 7 & 0.93 \\
\hline $\mathrm{AgI}$ & 4 & 4 & 206.5 & 1.467 & 2.545 & 4 & 7 & 1.01 \\
\hline $\mathrm{AuAl}$ & 5 & 2 & 333.0 & 1.551 & 2.338 & 7 & 3 & 1.00 \\
\hline $\mathrm{AuBe}$ & 5 & 1 & 607.7 & 1.873 & 2.060 & 7 & 2 & 1.08 \\
\hline $\mathrm{AuMg}$ & 5 & 2 & 307.9 & 1.195 & 2.443 & 7 & 2 & 1.05 \\
\hline $\mathrm{CuAl}$ & 3 & 1 & 293.0 & 0.958 & 2.339 & 3 & 3 & 0.94 \\
\hline $\mathrm{CuBr}$ & 3 & 3 & 314.8 & 2.056 & 2.173 & 3 & 7 & 1.11 \\
\hline $\mathrm{CuCl}$ & 3 & 2 & 415.3 & 2.293 & 2.050 & 3 & 7 & 1.07 \\
\hline $\mathrm{CuF}$ & 3 & 1 & 622.6 & 3.341 & 1.745 & 3 & 7 & 1.05 \\
\hline $\mathrm{CuI}$ & 3 & 4 & 264.5 & 1.746 & 2.338 & 3 & 7 & 1.12 \\
\hline $\mathrm{CuO}$ & 3 & 1 & 640.2 & 3.086 & 1.724 & 3 & 6 & 1.01 \\
\hline $\mathrm{CuTe}$ & 3 & 4 & 252.7 & 1.597 & 2.349 & 3 & 6 & 1.12 \\
\hline $\mathrm{FeO}$ & 3 & 1 & 965.0 & 6.824 & 1.570 & 3 & 6 & 1.78 \\
\hline $\mathrm{FeO}^{-}$ & 3 & 1 & 740.0 & 4.013 & 1.630 & 3 & 7 & 1.06 \\
\hline $\mathrm{HfO}$ & 5 & 1 & 974.1 & 8.212 & 1.723 & 4 & 6 & 2.33 \\
\hline $\mathrm{IrC}$ & 5 & 1 & 1060.1 & 7.480 & 1.680 & 7 & 4 & 1.85 \\
\hline $\mathrm{IrO}$ & 5 & 1 & 909.4 & 7.197 & 1.722 & 7 & 6 & 1.54 \\
\hline $\mathrm{LaF}$ & 3 & 1 & 570.0 & 3.199 & 2.026 & 3 & 7 & 1.45 \\
\hline $\mathrm{LaO}$ & 3 & 1 & 812.8 & 5.581 & 1.826 & 3 & 6 & 2.11 \\
\hline $\mathrm{LaS}$ & 3 & 2 & 456.7 & 3.194 & 2.355 & 3 & 6 & 2.26 \\
\hline $\mathrm{LuF}$ & 5 & 1 & 611.8 & 3.779 & 1.917 & 7 & 7 & 0.98 \\
\hline $\mathrm{LuO}$ & 5 & 1 & 842.5 & 6.129 & 1.790 & 7 & 6 & 1.45 \\
\hline $\mathrm{MnO}$ & 3 & 1 & 839.6 & 5.145 & 1.769 & 3 & 6 & 1.80 \\
\hline $\mathrm{NbN}$ & 4 & 1 & 1002.5 & 7.205 & 1.662 & 4 & 5 & 2.05 \\
\hline $\mathrm{NbO}$ & 4 & 1 & 989.0 & 7.864 & 1.690 & 4 & 6 & 2.13 \\
\hline $\mathrm{NiSi}$ & 3 & 2 & 467.4 & 2.430 & 2.032 & 3 & 4 & 1.47 \\
\hline $\mathrm{PtC}$ & 5 & 1 & 1051.1 & 7.359 & 1.677 & 7 & 4 & 1.81 \\
\hline $\mathrm{PtO}$ & 5 & 1 & 851.1 & 6.309 & 1.727 & 7 & 6 & 1.36 \\
\hline PtSi & 5 & 2 & 549.0 & 4.360 & 2.063 & 7 & 4 & 1.79 \\
\hline $\mathrm{RhC}$ & 4 & 1 & 1049.9 & 6.979 & 1.613 & 4 & 4 & 2.07 \\
\hline $\mathrm{ScCl}$ & 3 & 2 & 447.4 & 2.320 & 2.229 & 3 & 7 & 1.33 \\
\hline $\mathrm{ScF}$ & 3 & 1 & 735.6 & 4.257 & 1.788 & 3 & 7 & 1.42 \\
\hline $\mathrm{ScN}$ & 3 & 1 & 795. & 3.98 & 1.687 & 3 & 5 & 1.36 \\
\hline $\mathrm{ScO}$ & 3 & 1 & 965.0 & 6.472 & 1.668 & 3 & 6 & 1.96 \\
\hline $\mathrm{TaO}$ & 5 & 1 & 1028.7 & 9.163 & 1.667 & 7 & 6 & 1.82 \\
\hline $\mathrm{TiO}$ & 3 & 1 & 1009.0 & 7.192 & 1.620 & 3 & 6 & 2.03 \\
\hline TiS & 3 & 2 & 558.4 & 3.523 & 2.083 & 3 & 6 & 1.84 \\
\hline TiN & 3 & 1 & 1039. & 6.89 & 1.582 & 3 & 5 & 2.01 \\
\hline VN & 3 & 1 & 1033. & 6.91 & 1.566 & 3 & 5 & 1.96 \\
\hline VO & 3 & 1 & 1011.3 & 7.335 & 1.589 & 3 & 6 & 1.97 \\
\hline
\end{tabular}

Table 4 (continued)

\begin{tabular}{|c|c|c|c|c|c|c|c|c|}
\hline \multicolumn{3}{|l|}{ Species } & \multirow{2}{*}{$\begin{aligned} \omega_{\mathrm{e}} \\
380.7\end{aligned}$} & \multirow{2}{*}{$\begin{array}{l}k_{\mathrm{e}} \\
2.143\end{array}$} & \multirow{2}{*}{$\begin{array}{l}r_{\mathrm{e}} \\
2.406\end{array}$} & \multirow{2}{*}{$\frac{z_{1}}{4}$} & \multirow{2}{*}{$\frac{z_{2}}{7}$} & \multirow{2}{*}{$\begin{array}{l}n \\
1.28\end{array}$} \\
\hline $\mathrm{YCl}$ & 4 & 1 & & & & & & \\
\hline YF & 4 & 1 & 631.3 & 3.675 & 1.926 & 4 & 7 & 1.27 \\
\hline YO & 4 & 1 & 861.0 & 5.921 & 1.790 & 4 & 6 & 1.85 \\
\hline $\mathrm{ZrO}$ & 4 & 1 & 969.8 & 7.524 & 1.712 & 4 & 6 & 2.10 \\
\hline
\end{tabular}

Columns 2 and 3 identify the period of the periodic table to which each atom in the diatomic molecule belongs. The vibrational frequencies $\left(\omega_{\mathrm{e}}\right)$ are in $\mathrm{cm}^{-1}$ and the force constants $\left(k_{\mathrm{e}}\right)$ in mdyne/A. The internuclear distances are in $\AA$, while $z_{1}$ and $z_{2}$ are the number of valence electrons from atoms 1 and 2 . Most of the vibrational frequencies, force constants and internuclear distances are from Refs. [4,56,57], for $\{\mathrm{PtSi}\}$ from Ref. [67], for $\{\mathrm{NiSi}\}$ from Ref. [68], for $\{\mathrm{AlCu}\}$ from Ref. [69], for $\{\mathrm{CuSi}\}$ from Ref. [70], for $\{\mathrm{ScN}\}\{\mathrm{VN}\}$ $\{\mathrm{TiN}\}$ from Ref. [71].

the metallic oxides and sulfides have somewhat higher bond orders (1.06-1.49) indicating likely double bonds as might be expected. Various rare gas dimers have extremely small bond orders, as expected for van der Waals complexes.

In Table 3, we have calculated bond orders for diatomic molecules formed from two transition metal atoms using Guggenheimer's parameters for covalent bonds. These present a problem in that the values for $z_{1}$ and $z_{2}$ cannot be easily obtained by examination of the s- and p- electrons as in Tables 1 and 2 . Instead we utilize the values of Guggenheimer, i.e. that $z=3,4$ or 7 for members of the third, fourth and fifth row transition metals respectively. It is especially encouraging that the experimental bond orders for $\mathrm{Cu}_{2}, \mathrm{Ag}_{2}$ and $\mathrm{Au}_{2}$ as well as the mixed dimers $\mathrm{AgAu}, \mathrm{CuAg}$, and $\mathrm{CuAu}$, are very close to one. This is as expected since all the atoms involved have a $\mathrm{d}^{10} \mathrm{~s}^{1}$ configuration. Table 3 includes only those dimers for which accurate internuclear distances are known. The observed values should be compared with those calculated from Pauling's relationship (Eq. (11), see Ref. [34]). These are all somewhat lower, but perhaps more realistic. $\mathrm{Mo}_{2}$ for example has a bond order $n=2.91$, indicating a triple or even larger bond. [The Pauling bond order $n_{\mathrm{P}}$ is 5.38 , indicating the (unlikely) participation of 10-11 electrons in bonding.] Other rather large values of the experimental bond order from Eq. (14) are obtained for $\mathrm{V}_{2}, \mathrm{Nb}_{2}$ and $\mathrm{VNb}$, reflecting considerable participation of d-electrons in bonding. On the contrary, for $\mathrm{Ni}_{2}$ and $\mathrm{Fe}_{2}$ the values indicate 
essentially no d-electron participation. Note the exceptionally low values for $\mathrm{Mn}_{2}, \mathrm{Zn}_{2}, \mathrm{Cd}_{2}$ and $\mathrm{Hg}_{2}$ reflecting the van der Waals nature of the bonding in these dimers.

In Table 4, we present calculations of bond order for diatomic molecules formed from one transition metal atom and another atom from elsewhere in the periodic table, mostly halides and oxides. Note the especially large values obtained for the oxides as well as the carbides, indicating considerable involvement of delectrons from the transition metal atoms. On the other hand, species involving the coinage metals, as expected, all have bond orders indicating single bonds.

It is clear that the formula presented in Eq. (14) for an experimental bond order fits the criteria suggested in the previous section. It can be calculated from easily measured quantities, i.e. the force constant and the internuclear distance, and there are only two adjustable parameters ( $C$ and $s$ ). It is apparently applicable over large parts of the periodic table, including the transition metals. At this time we cannot test possible applications to the actinides since force constant and internuclear distances are not available. Most importantly, this formula gives reasonable values. Almost all the species for which it is expected to be a formal single bond result in an experimental value of very close to one. The only serious exception is for $F_{2}$. Van der Waals complexes have smaller values, while those species for which we expect double and triple formal bonds have larger values, usually in very reasonable ranges.

The next question of interest is whether the above formula for an experimental bond order can be extended to polyatomic molecules. Polyatomic molecules present an additional difficulty in that there is ambiguity as to the way a force constant is measured. The value obtained depends on the force field chosen, and thus values can vary considerably. Perhaps the simplest force field is called the valence force field [47] in which stretching force constants are defined along chemical bonds, and bending force constants are assumed to account for angular motions of bonds, as well as some stretch-stretch and stretchbend interaction constants. These constants are then determined experimentally by finding the set of values, which best fit the observed normal vibrational frequencies. However, it was found that in order to more accurately represent observed frequencies, additional force constants should to be added to the force field. In addition to interaction constants (such as stretch-stretch, and stretch bend interactions), certain non-bonded interactions were also included [48]. This so-called Urey-Bradley force field currently represents the best means of fitting observed frequencies. Despite this, we feel that the valence force field is more consistent with our understanding of the influence of bond order in considerations of molecular bonding. As observed in the previous section, there is an intimate connection between bond order and bond electron density Eq. (10). It is found that as the non-bonded force constants in a Urey-Bradley force field are increased, the stretching force constants must be decreased in order to fit observed frequencies. The bond order is a measure of the total electron density involved in bonding, and therefore, unless we wish to include bond orders for non-bonded interactions, the simpler valence force field may be more appropriate, and we shall adopt it here. In Table 5, we present bond order calculations for several polyatomic molecules (plus CO, for comparison) using Eq. (14)

Table 5

Bond orders for several bonds in polyatomic molecules using Eq (14), with $C=2.738$ and $s=2.46$

\begin{tabular}{lllll}
\hline Molecule & Bond & $r_{\mathrm{e}}(\AA)$ & $k_{\mathrm{e}}($ mdyne $/ \AA)$ & $n$ \\
\hline $\mathrm{C}_{2} \mathrm{H}_{6}$ & $\mathrm{C}-\mathrm{C}$ & 1.55 & 4.33 & 1.16 \\
$\mathrm{C}_{2} \mathrm{H}_{4}$ & $\mathrm{C}=\mathrm{C}$ & 1.33 & 9.60 & 1.80 \\
$\mathrm{C}_{2} \mathrm{H}_{2}$ & $\mathrm{C} \equiv \mathrm{C}$ & 1.20 & 17.2 & 2.49 \\
$\mathrm{C}_{6} \mathrm{H}_{6}$ & $\mathrm{C}-\mathrm{C}$ & 1.39 & 7.83 & 1.63 \\
$\mathrm{C}_{2} \mathrm{H}_{6}$ & $\mathrm{C}-\mathrm{H}$ & 1.06 & 4.79 & 1.01 \\
$\mathrm{C}_{6} \mathrm{H}_{6}$ & $\mathrm{C}-\mathrm{H}$ & 1.084 & 5.00 & 1.11 \\
$\mathrm{CH}_{3} \mathrm{~F}$ & & & & \\
$\mathrm{CH}_{3} \mathrm{Cl}$ & $\mathrm{C}-\mathrm{F}$ & 1.358 & 5.96 & 0.873 \\
$\mathrm{CH}_{3} \mathrm{Br}$ & $\mathrm{C}-\mathrm{Cl}$ & 1.66 & 3.64 & 0.874 \\
$\mathrm{CH}_{3} \mathrm{I}$ & $\mathrm{C}-\mathrm{Br}$ & 1.91 & 3.129 & 1.06 \\
$\mathrm{CH}_{3} \mathrm{C} \equiv \mathrm{N}$ & $\mathrm{C}-\mathrm{I}$ & 2.10 & 2.648 & 1.13 \\
$\mathrm{HC} \equiv \mathrm{N}$ & $\mathrm{C}-\mathrm{C}$ & 1.49 & 4.94 & 1.20 \\
$\mathrm{CH}_{3} \mathrm{C} \equiv \mathrm{N}$ & $\mathrm{C} \equiv \mathrm{N}$ & 1.15 & $17.73)$ & 2.04 \\
$\left(\mathrm{CH}_{3}\right)_{2} \mathrm{CNOH}$ & $\mathrm{C} \equiv \mathrm{N}$ & 1.16 & 17.73 & 2.09 \\
$\mathrm{CH}_{3} \mathrm{~N} \equiv \mathrm{C}$ & $\mathrm{C}=\mathrm{N}$ & 1.34 & 10.0 & 1.65 \\
$\mathrm{CH}_{3} \mathrm{NH}$ & $\mathrm{C}-\mathrm{N}$ & 1.46 & 5.18 & 1.21 \\
$\mathrm{C}_{2} \mathrm{O}$ & $\mathrm{C}-\mathrm{N}$ & 1.48 & 4.86 & 1.04 \\
$\mathrm{H}_{2} \mathrm{C}=\mathrm{O}$ & $\mathrm{C} \equiv \mathrm{O}$ & 1.13 & 18.53 & 1.91 \\
$\mathrm{CH}_{3} \mathrm{OH}$ & $\mathrm{C}=\mathrm{O}$ & 1.21 & 12.1 & 1.44 \\
\hline & $\mathrm{C}-\mathrm{O}$ & 1.434 & 5.77 & 1.04 \\
\hline
\end{tabular}

From Refs. [1,57,72-82]. 
with the values of $C$ and $s$ obtained by Guggenheimer for covalently bonded species.

In the first group of Table 5, we include several hydrocarbons. Note that the values obtained for the $\mathrm{C}-\mathrm{H}$ and $\mathrm{C}-\mathrm{C}$ bonds in ethylene, acetylene are all in keeping with the results for formally single, double and triple bonds in diatomic molecules. A word should be said about the results for $\mathrm{C}-\mathrm{C}$ bonds in ethane and benzene. The value of 1.16 in ethane seems somewhat high for a single bond. However, it is well known that in ethane the bond length is shorter and the force constant larger than expected for a single bond. In order to explain this observation, Mulliken introduced the concept of hyperconjugation [49], in which ionic valence-bond structures from the $\mathrm{C}-\mathrm{H}$ bonds can add electron density to the $\pi$-orbital of the $\mathrm{C}-\mathrm{C}$ bond. Applying a simple LCAO-molecular orbital calculation, he obtained a value of 1.12 for the bond order. For benzene, the value calculated here is 1.63 , which is quite close to that calculated by Coulson [8] (1.67).

The second group of Table 5 includes calculation of the bond order of $\mathrm{C}-\mathrm{X}$ bonds of methyl halides, methyl cyanide and methyl isocyanide. Note that all the values are close to one, and are thus consistent with expectations for a formally single bond. The trend in bond order in the methyl halides, for which the bond order increases in going from $\mathrm{F}$ to I is just the opposite of the decrease observed in many series of diatomic halides in Table 1. Also, the rather larger values of the $\mathrm{C}-\mathrm{C}$ bond orders for the cyanide (1.20) and isocyanide (1.21) are attributable to hyperconjugation effects [49].

In the third group of molecules we have calculated the bond order for several $\mathrm{C}-\mathrm{N}$ bonds. In $\mathrm{HCN}$ and $\mathrm{CH}_{3} \mathrm{CN}$ we find bond orders above 2, consistent with formal triple bond calculations in diatomic molecules. For $\mathrm{CH}_{3} \mathrm{NH}_{2}$ the $\mathrm{C}-\mathrm{N}$ bond order is 1.04 , consistent with that expected for a formally single bond.

In the fourth group of molecules in Table 5, we have determined the experimental bond order for various $\mathrm{C}-\mathrm{O}$ bonds (repeating the diatomic molecule CO from Table 1 for comparison). For the formally triple $\mathrm{C}=\mathrm{O}$ bond we find a bond order of 1.91. The formally double bond in formaldehyde $\left(\mathrm{H}_{2} \mathrm{C}=\mathrm{O}\right)$ has and experimental bond order of 1.44, while the formally single bond $(\mathrm{C}-\mathrm{O})$ in methanol has an experimental bond order of 1.04. Once again these
Table 6

Bond orders for bonds in biphenyl. Bonds are numbered from the bridging bond $\mathrm{C}_{1}$

\begin{tabular}{llll}
\hline Bond & $r_{\mathrm{e}}$ & $k_{\mathrm{e}}$ & $n$ \\
\hline $\mathrm{C}_{1}-\mathrm{C}_{1}$ & 1.507 & 4.40 & 1.10 \\
$\mathrm{C}_{1}-\mathrm{C}_{2}$ & 1.372 & 6.49 & 1.29 \\
$\mathrm{C}_{2}-\mathrm{C}_{3}$ & 1.416 & 6.49 & 1.40 \\
$\mathrm{C}_{3}-\mathrm{C}_{4}$ & 1.376 & 6.49 & 1.30 \\
$\mathrm{C}_{4}-\mathrm{H}$ & 1.06 & 5.12 & 1.08 \\
\hline
\end{tabular}

Data from Ref. [50].

results are consistent with those found for diatomic molecules.

In Table 6, we calculate the bond orders for the bonds in biphenyl using the data of Zerbi and Sandroni [50]. The bonds are numbered starting from the bridge carbon atoms $\left(\mathrm{C}_{1}\right)$. It can be seen that, once again the experimental bond orders are reasonable, in relation to those calculated for diatomic molecules. The ring $\mathrm{C}-\mathrm{C}$ bonds are all approximately what would be expected for a double bond (although somewhat lower than the bond orders in benzene), the $\mathrm{C}-\mathrm{H}$ bond order is 1.08 , as might be expected, and the bridging bond has a bond order of 1.10, slightly larger than a formal single bond, but not much. This is consistent with the usual description of this bond as an 'essential' single bond [7].

In Table 7 we present calculations of the experimental bond orders for various bonds in

Table 7

Bond orders for bonds in Ni-porphine. Only one-quarter of the planar $D_{4 h}$ molecule is shown

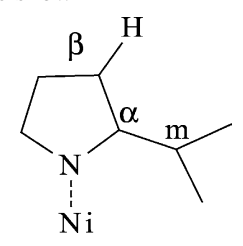

\begin{tabular}{llll}
\hline Bond & $k_{\mathrm{e}}$ & $r_{\mathrm{e}}$ & $n$ \\
\hline $\mathrm{C}_{\beta}-\mathrm{C}_{\beta}$ & 7.12 & 1.352 & 1.37 \\
$\mathrm{C}_{\alpha}-\mathrm{C}_{\mathrm{m}}$ & 6.98 & 1.383 & 1.42 \\
$\mathrm{C}_{\alpha}-\mathrm{N}$ & 5.64 & 1.380 & 1.02 \\
$\mathrm{C}_{\alpha}-\mathrm{C}_{\beta}$ & 5.02 & 1.440 & 1.12 \\
$\mathrm{C}_{\beta}-\mathrm{H}$ & 5.20 & 1.090 & 1.17 \\
$\mathrm{Ni}-\mathrm{N}$ & 1.68 & 1.955 & 0.598
\end{tabular}

Data from Ref. [83]. 
$\mathrm{Ni}$-porphine, using data from $\mathrm{Li}$ et al. [51] The molecule is a planar porphyrin derivative with $D_{4 h}$ symmetry, and in the diagram we present only onequarter of the molecule for convenient identification of the bonds. Note that the first two bonds listed $\left(\mathrm{C}_{\beta}-\right.$ $\mathrm{C}_{\beta}$ and $\mathrm{C}_{\beta}-\mathrm{C}_{\mathrm{m}}$ ) have bond orders around 1.4, consistent with formal double bonds, while the $\mathrm{C}_{\alpha}-\mathrm{N}$ and $\mathrm{C}_{\alpha}-\mathrm{C}_{\beta}$ are more nearly single bonds. The Ni-N bond, involving d-orbitals on the $\mathrm{Ni}$ atom has an experimental bond order of only 0.598 , but there are four such bonds in the molecule. Assuming that the valence force constants are used, it is clear from the bond orders listed in Tables 5-7 that Eq. (14) gives reasonable values for the bond orders for polyatomic molecules as well as for diatomic molecules.

Another approach to an experimental bond order may be obtained by examination of the Bader formula for bond order in terms of the electron density at the bond critical point Eq. (10). Recent advances in X-ray crystallography, as well as availability of a synchrotron source with a high quality detector, now enable us to conveniently obtain good experimental electron density maps at least for molecules which can be crystallized [52-55]. It is therefore worthwhile to examine ways in which the Bader formula can be extended to make it more generally applicable. The values recommended for the parameters $A$ and $B$ are useful only for $\mathrm{C}-\mathrm{C}$ bonds, and any attempt to use the formula as is for other bonds fails for several reasons. First, since in different rows of the periodic table, increasingly filled shells contribute to the electron density, we might expect the best values of $A$ and $B$ might vary. For example, $B$ was interpreted above as the critical density of a single bond, but this density should change with periodic table row. It is likely therefore that better results will be obtained if $A$ and $B$ were replaced with $A_{i j}$ and $B_{i j}$, where $i$ and $j$ refer to rows in the periodic table. Secondly, as the Guggenheimer formula above shows, the bond order should vary inversely with $\sqrt{z_{1} z_{2}}$ where $z_{1}$ and $z_{2}$ are the number of valence electrons for each atom joined by the bond. If we choose $\alpha$ to be the value of $\sqrt{z_{1} z_{2}}$ for some reference bond (for a given $i$ and $j$ ), then we suggest a generalization of the Bader formula as:

$n_{\mathrm{B}}=\frac{\alpha}{\sqrt{z_{1} z_{2}}} \exp \left[A_{i j}\left(\rho_{\mathrm{b}}-B_{i j}\right)\right]$
In general it is difficult to obtain experimental values of $\rho_{\mathrm{b}}$ with which to determine corresponding experimental values of $A_{i j}$ and $B_{i j}$. However, in order to test this formula, we may use the experimental bond orders obtained from Eq. (14) in conjunction with theoretical values of $\rho_{\mathrm{b}}$. For example, using the experimental values of $n$ for $\mathrm{C}-\mathrm{C}$ bonds from Table 5 $(1.16,1.63,1.80$, and 2.49 for ethane, benzene, ethylene, and acetylene), $\rho_{\mathrm{b}}$ from 6-31G* SCF calculations [27] and $\alpha=4$, we obtain values of $A_{11}=0.666$ and $B_{11}=1.49$. [Note that with this formula (15), the meaning of $B_{11}$ must be reinterpreted. It now represents the critical density of the formally single bond for which $\sqrt{z_{1} z_{2}}=\alpha$.] Using these parameters, we may then calculate 'experimental' bond orders for cases in which we have an experimental value of $\rho_{\mathrm{b}}$. Such values have been obtained for peptide linkages $\left(\mathrm{C}_{\alpha}(\mathrm{NH})(\mathrm{C}=\mathrm{O}) \mathrm{C}_{\alpha}\right)$ in protiens [52], and we list them in Table 8, along with calculated values of $n_{\mathrm{B}}$. For comparison we include values of $n$ obtained directly using force constants and internuclear distances from Eq. (14). It can be seen that with this procedure, reasonable values of bond order are obtained, and that there is fairly good agreement between the two experimental methods of determining bond order.

In many ways, the Bader formula for bond order is more attractive than that of Eq. (14), in that it provides a direct connection between electron density and bond order. Furthermore it depends on only one measured quantity, while Eq. (14) requires two. However, it is difficult to obtain accurate measurements of $\rho_{\mathrm{b}}$ since a good crystalline sample must be prepared, and relatively few measurements currently exist. In addition, more adjustable parameters must be used

Table 8

Calculation of bond orders $\left(n_{\mathrm{B}}\right)$ in peptides $\left(\mathrm{C}_{\alpha}(\mathrm{NH})(\mathrm{C}=\mathrm{O}) \mathrm{C}_{\alpha}\right)$ using experimental critical densities $\left(\rho_{\mathrm{b}}\right)$ in Eq. (15) $(A=0.666$, $B=1.49, \alpha=4)$ and $(n)$ using experimental force constants and internuclear distances in Eq. (14)

\begin{tabular}{lcclll}
\hline Bond & $r_{\mathrm{e}}(\AA)$ & $k_{\mathrm{e}}(\mathrm{mdyne} / \AA)$ & $\rho_{\mathrm{b}}\left(\AA^{-3}\right)$ & $n_{\mathrm{B}}$ & $n$ \\
\hline $\mathrm{C}=\mathrm{O}$ & 1.236 & 16.8 & 2.80 & 1.95 & 2.11 \\
$\mathrm{C}-\mathrm{N}$ & 1.338 & 10.0 & 2.40 & 1.64 & 1.65 \\
$\mathrm{~N}-\mathrm{C}_{\alpha}$ & 1.447 & 6.50 & 1.80 & 1.10 & 1.32 \\
$\mathrm{C}-\mathrm{C}_{\alpha}$ & 1.512 & 4.50 & 1.70 & 1.15 & 1.15 \\
\hline
\end{tabular}

Data for $r_{\mathrm{e}}$ and $\rho_{\mathrm{b}}$ are taken from Ref. [84]. Data for $k_{\mathrm{e}}$ are from Ref. [47] except for $\mathrm{C}-\mathrm{N}$ which is from Ref. [78]. 
in order to account for the increasing electron density contributed by core electrons going down the periodic table. Eq. (14) is remarkable in that only two adjustable parameters fit a wide variety of data throughout the periodic table, and depends on easily obtainable experimental parameters. The general agreement between the two techniques for the admittedly limited number of cases listed in Table 8 is at least encouraging.

\section{Conclusions}

In the final analysis, it is probably true that the bond order has use mainly as a comparative tool, enabling us to examine the way in which bonding changes from molecule to molecule, within a molecule, or even during the course of a chemical change. It is a tool to enable us to identify the nature of bonding in the ground state of a molecule, often against the benchmark of a single bond. As we have seen in the introduction, there are many theoretical definitions of bond order, each of which has a value in various situations, but all require a good ground state wave function or at least electron density. The problem with these definitions is that they are all difficult to determine experimentally, and thus lack the value of an experimental check. One might be tempted to regard the bond order operator $\mathbf{I}_{\mathrm{AB}}=-2$ $\boldsymbol{\sigma}_{\mathrm{AB}}$ Eq. (5) of Yamasaki and Goddard [15] as a candidate for experimental verification, since it is a Hermetian operator and may thus be associated with an observable. However, it is difficult to measure the correlation between fluctuations of the electronic charges directly.

In this article we have explored two very different experimental definitions of bond order. That due to Bader Eq. (10), which we have modified to be more generally applicable. Eq. (15), is quite attractive due to the direct connection with electron density measurements. Such determinations are becoming increasingly available, especially for molecules of biological interest. They are, however, limited to molecules, which can be readily crystallized. Furthermore, due to large variations in the core electron density, considerable parameterization is likely to be needed in order to extend the definition across the periodic table, and enable useful comparisons. Our second recommendation involved an inversion of an equation due to Guggenheimer. One advantage of this expression is that it involves readily measurable parameters $\left(r_{\mathrm{e}}\right.$ and $k_{\mathrm{e}}$ ). In addition there are only two adjustable parameters $(C$ and $s$, which are applicable throughout the periodic table (except for certain classes of bonds). The theoretical underpinnings of this formula are less clear. Guggenheimer [31] gave a heuristic justification for the $\sqrt{z_{1} z_{2}}$ dependence and, using the Fermi expression for the energy of an electron gas, was able to predict a value of 2.67 for $s$, compared with the value of 2.46 derived empirically by Guggenheimer by fitting several observed force constants to internuclear distances. We tried using $s=2.67$ in the expression for bond order (adjusting $C$ accordingly) but obtained results which were somewhat less satisfactory than those obtained using the empirical value. Additionally, by setting $n=1$ in Eq. (14), we find an interpretation of the meaning of $C$ that:

$C=\frac{k_{\mathrm{e}}^{(1)} r_{\mathrm{e}}^{(1) s}}{\sqrt{z_{1} z_{2}}}$

where $k_{\mathrm{e}}^{(1)}$ and $r_{\mathrm{e}}^{(1)}$ are the force constant and internuclear distance for a formally single bond [34].

The remarkable thing about this Eq. (14) expression for bond order is the applicability throughout the periodic table, both for diatomic molecules and polyatomic molecules with a minimum of adjustable parameters. It is especially encouraging that, to the extent a comparison is possible, the Bader formula and the inverted Guggenheimer formula give results which are very close, despite the considerable differences in the experimental parameters upon which they depend.

\section{Acknowledgements}

This work was supported by the National Science Foundation under Cooperative Agreement No. RII9353488 and Grant No. CHE-0091362 and by the City University of New York PSC-BHE Faculty Research Award Program. One of us (JJ) was supported by NSF (CIRE) grant No. CHE-9872777. The authors are also indebted to Haiyan $\mathrm{Lu}$ and Dr Bing Zhao for assistance in preparing this work. 


\section{References}

[1] L. Pauling, The Nature of The Chemical Bond, Cornell University Press, Ithaca, 1960.

[2] L. Pauling, L.O. Brockway, J.Y. Beach, J. Am. Chem. Soc. 57 (1935) 2705.

[3] See for example, C.W. Bauschlicher, A. Ricca, Mol. Phys. 101 (2003) 93.

[4] M.D. Morse, Chem. Rev. 86 (1986) 1049.

[5] R. Guo, K. Balasubramanian, J. Chem. Phys. 118 (2003) 142.

[6] R.F.W. Bader, W.H. Henneker, P.E. Cade, J. Chem. Phys. 46 (1967) 3341

[7] M.J.S. Dewar, The Molecular Orbital Theory of Organic Chemistry, McGraw-Hill, New York, 1969.

[8] C.A. Coulson, Proc. Roy. Soc. London A169 (1939) 413.

[9] R.S. Mulliken, J. Chem. Phys. 23 (1955) 1841.

[10] R.J. Boyd, Can J. Chem. 51 (1973) 1151.

[11] A.E. Reed, P.v.R. Schleyer, Inorg. Chem. 27 (1988) 3969. J. Am. Chem. Soc. 112 (1990) 1434.

[12] J. Cioslowski, S.T. Mixon, J. Am. Chem. Soc. 113 (1991) 4142.

[13] R.F.W. Bader, T.T. Nguyen-Dang, Adv. Quantum. Chem. 14 (1981) 63.

[14] D.B. Chesnut, Chem. Phys. 291 (2003) 141.

[15] T. Yamasaki, W.A. Goddard, J. Phys. Chem. A 102 (1998) 2919.

[16] M.S. Giambiagi, M. Giambiagi, F.E. Jorge, Theoret. Chim. Acta. 68 (1985) 337.

[17] K.B. Wiberg, Tetrahedron 24 (1968) 1083.

[18] L. Salem, Molecular Orbital Theory of Conjugated Systems, W.A. Benjamin, New York, 1966.

[19] D.R. Armstrong, P.G. Perkins, J.J.P. Stewart, J. Chem. Soc. Dalton (1973) 838

[20] M.A. Natiello, J.A. Medrano, Chem. Phys. Lett. 105 (1984) 180.

[21] I. Mayer, Int. J. Quantum Chem. XXIX (73) (1986) 477.

[22] R.L. Fulton, J. Phys. Chem. 97 (1993) 7516.

[23] X. Fradera, M.A. Austen, R.F.W. Bader, J. Phys. Chem. 103 (1999) 304.

[24] J.G. Angyan, E. Rosta, P.R. Surjan, Chem. Phys. Lett. 299 (1999) 1.

[25] R.F.W. Bader, Atoms in Molecules: A Quantum Theory, Clarendon Press, Oxford, 1994.

[26] R.F.W. Bader, H. Essen, J. Chem. Phys. 80 (1984) 1943.

[27] R.F.W. Bader, T.S. Slee, D. Cremer, E. Kraka, J. Am. Chem. Soc. 105 (1983) 5061.

[28] D. Cremer, E. Kraka, T.S. Slee, R.F.W. Bader, C.D.H. Lau, T.T. Nguyen-Dang, P.J. MacDougall, J. Am. Chem. Soc. 105 (1983) 5069

[29] R. Ponec, G. Yuzhakov, D.L. Cooper, J. Phys. Chem. 107 (2003) 2100

[30] S.T. Howard, O. Lamarche, J. Phys. Org. Chem. 16 (2003) 133.

[31] K.M. Guggenheimer, Proc. Phys. Soc. 63 (1946) 456 see also page 459.

[32] H.S. Johnston, Gas Phase Reaction Rate Theory, The Ronald Press Co, 1966.

[33] J.R. Lombardi, B. Davis, Chem. Rev. 102 (2002) 2431.

[34] J.L. Jules, J.R. Lombardi, J. Phys. Chem. 107 (2003) 1268.
[35] J.L. Kavanau, J. Chem. Phys. 12 (1944) 467. J.L. Kavanau, J. Chem. Phys. 17 (1949) 738.

[36] W. Gordy, J. Chem. Phys. 14 (1946) 305.

[37] P. Politzer, S. Ranganathan, Chem. Phys. Lett. 124 (1986) 527

[38] R.F. Borkman, G. Simons, R.G. Parr, J. Chem. Phys. 50 (1969) 58

[39] R.G. Parr, R.J. White, J. Chem. Phys. 49 (1968) 1059.

[40] R.G. Parr, R.F. Borkman, J. Chem. Phys. 49 (1968) 1055.

[41] P. Politzer, J. Chem. Phys. 51 (1969) 459.

[42] P. Politzer, J. Chem. Phys. 50 (1969) 2780.

[43] K. Jug, J. Am. Chem. Soc. 99 (1977) 7800.

[44] P. Politzer, J. Am. Chem. Soc. 91 (1969) 6235.

[45] P. Politzer, Inorg. Chem. 16 (1977) 3350.

[46] S.R. Radel, M.H. Navidi, Chemistry, West Publishing, St Paul Minn, 1994.

[47] G. Herzberg, Infrared and Raman Spectra, D. Van Nostrand Co, Princeton, 1966

[48] M. Diem, Introduction to Modern Vibrational Spectroscopy, Wiley, New York, 1993.

[49] R.S. Mulliken, C.A. Rieke, W.G. Brown, J. Am. Chem. Soc. 63 (1941) 41.

[50] G. Zerbi, S. Sandroni, Spectrochimica Acta 24A (1967) 511.

[51] X.-Y. Li, R.S. Czernuszewicz, J.R. Kincaid, Y.O. Su, T.G. Spiro, J. Phys. Chem. 94 (1990) 31.

[52] T. Koritsansky, R. Flaig, D. Zobel, H.-G. Krane, W. Morgenroth, P. Luger, Science 279 (1998) 356.

[53] L. Claude, S. Mohamed, P. Sebastien, J. Mol. Struct. 647 (2003) 53.

[54] M. Souhassou, L. Claude, N.-E. Ghermani, M.M. Rohmer, R. Wiest, M. Benard, R.H. Blessing, J. Am. Chem. Soc. 114 (1992) 2371.

[55] V. Pichon-Pesme, C. Lecomte, H. Lachekar, J. Phys. Chem. 99 (1995) 6242.

[56] K.P. Huber, G. Hertzberg, Molecular Spectra and Molecular Structure, VNR Co, New York, 1979.

[57] G. Herzberg, Spectra of Diatomic Molecules, D. Van Nostrand Co., Inc, Princeton, 1959.

[58] C.A. Arrington, D.J. Brugh, M.D. Morse, M. Doverstäl, J. Chem. Phys. 102 (1995) 8704-8713.

[59] C.A. Arrington, M.D. Morse, M. Doverstäl, J. Chem. Phys. 102 (1995) 1895-1904.

[60] J.C. Fabbi, J.D. Langenberg, Q.D. Costello, M.D. Morse, J. Chem. Phys. 115 (2001) 7543. G.A. Bishea, M.D. Morse, J. Chem. Phys. 95 (1991) 5646.

[61] G.A. Bishea, M.D. Morse, Chem. Phys. Lett. 171 (1990) 430.

[62] G.A. Bishea, J.C. Pinegar, M.D. Morse, J. Chem. Phys. 95 (1991) 5630.

[63] E.M. Spain, M.D. Morse, J. Chem. Phys. 97 (1992) 4605.

[64] S.M. Sickafoose, J.D. Langenberg, M.D. Morse, J. Phys. Chem. A 104 (2000) 3521.

[65] Z. Fu, M.D. Morse, J. Chem. Phys. 90 (1989) 3417. E.M. Spain, M.D. Morse, J. Chem. Phys. 97 (1992) 4633.

[66] B. Zhao, H. Lu, I. Likhtina, J. Jules, J.R. Lombardi, J. Chem. Phys. 118 (2003) 9704.

[67] J.B. Paul, J.J. Scherer, C.P. Collier, R.J. Saykally, J. Chem. Phys. 104 (1996) 2782. L. Shao, S.M. Sickafoose, J.D. Langenberg, D.J. Brugh, M.D. Morse, J. Chem. Phys. 112 
(2000) 4118. M. Barysz, P. Pyykko, Chem. Phys. Lett. 368 (2003) 538.

[68] N.F. Lindholm, D.J. Brugh, G.K. Rothschopf, S.M. Sickafoose, M.D. Morse, J. Chem. Phys. 118 (2003) 2190.

[69] J.M. Behm, C.A. Arrington, J.D. Langenberg, M.D. Morse, J. Chem. Phys. 99 (1993) 6394.

[70] J.J. Scherer, J.B. Paul, C.P. Collier, R.J. Saykally, J. Chem. Phys. 102 (1995) 5190. P. Turski, M. Barysz, J. Chem. Phys. 113 (2000) 4654.

[71] J.F. Harrison, J. Phys. Chem. 100 (1996) 3513.

[72] B.P. Stoicheff, Can. J. Phys. 32 (1954) 339.

[73] F.J. Stiff, Chem. Phys. 7 (1939) 297.

[74] B.L. Crawford, S.R. Brinkley, J. Chem. Phys. 9 (1941) 69.

[75] F. Wu, S. Kiang, J. Chem. Phys. 7 (1939) 178.
[76] B.L. Crawford, F.A. Miller, J. Chem. Phys. 17 (1949) 249.

[77] G. Herzberg, Infrared and Raman Spectra, D. Van Nostrand Co., Inc, Princeton, 1966.

[78] H.J. Bernstein, J. Chem. Phys. 6 (1938) 718.

[79] R.G. Owens, E.F. Barker, J. Chem. Phys. 8 (1940) 229.

[80] J.T. Edsall, H. Scheinberg, J. Chem. Phys. 8 (1940) 520.

[81] G. Herzberg, Electronic Spectra of Polyatomic Molecules, D. Van Nostrand Co., Inc, Princeton, 1966.

[82] J.O. Halford, L.C. Anderson, G.H. Kissen, J. Chem. Phys. 5 (1937) 927.

[83] X.-Y. Li, R.S. Czernuszewicz, J.R. Kincaid, Y.O. Su, T.G. Spiro, J. Phys. Chem. 94 (1990) 31.

[84] L. Claude, S. Mohamed, P. Sebastien, J. Mol. Struct. 647 (2003) 53. 